\title{
Standardization and validation of a protocol of zeta potential evaluation by electrophoretic light scattering for nanomaterial characterization
}

\author{
Fanny Varenne ${ }^{a, b}$, Jérémie Botton ${ }^{c, d}$, Claire Merlet ${ }^{a, b}$, Jean-Jacques Vachon ${ }^{a, b}$, \\ Sandrine Geiger ${ }^{\mathrm{a}, \mathrm{b}, \mathrm{e}}$, Ingrid C. Infante ${ }^{\mathrm{e}}$, Mohamed Chehimi ${ }^{f}$, Christine Vauthier ${ }^{\mathrm{a}, \mathrm{b}^{*}}$. \\ a Univ Paris-Sud, Institut Galien Paris-Sud, Faculty of Pharmacy, Châtenay-Malabry, France \\ ${ }^{\text {b } C N R S ~ U M R ~ 8612, ~ I n s t i t u t ~ G a l i e n ~ P a r i s-S u d, ~ C h a ̂ t e n a y-M a l a b r y, ~ F r a n c e ~}$ \\ ' Univ Paris-Sud, Faculty of Pharmacy, Châtenay-Malabry, France \\ d INSERM UMR 1153, Epidemiology and Biostatistics Sorbonne Paris Cité Center (CRESS), Team " Early \\ Origin of the Child's Health and Development " (ORCHAD), University Paris Descartes, Paris, France \\ e Laboratory "Structures, Propriétés et Modélisation des Solides », UMR 8580, CNRS \& Centrale Supélec, \\ University Paris-Saclay, Châtenay-Malabry, France \\ ${ }^{f}$ Paris Est University, ICMPE (UMR 7182), SPC, UPEC, Thiais, France
}

Published in: Colloids Surf A Physicochem Eng Asp. 2015; 486:218-231. Available on https://doi.org/10.1016/j.colsurfa.2015.08.044. Erratum: Colloids Surf A Physicochem Eng Asp. 2016;498:283-284. Available on: https://doi.org/10.1016/j.colsurfa.2016.02.030.

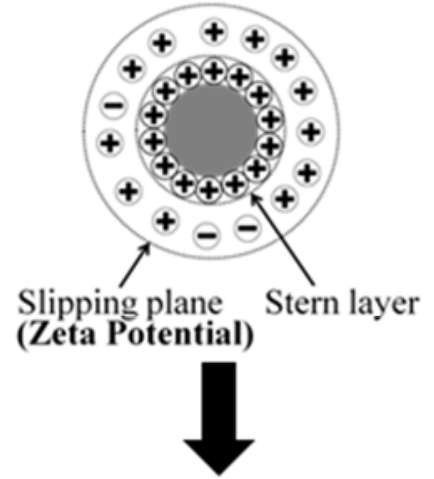

ELS measurement protocol using

PALS to evaluate electrophoretic mobility and zeta potential

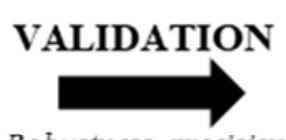

Robustness, precision and trueness (using nested design and $A N O V A$ )

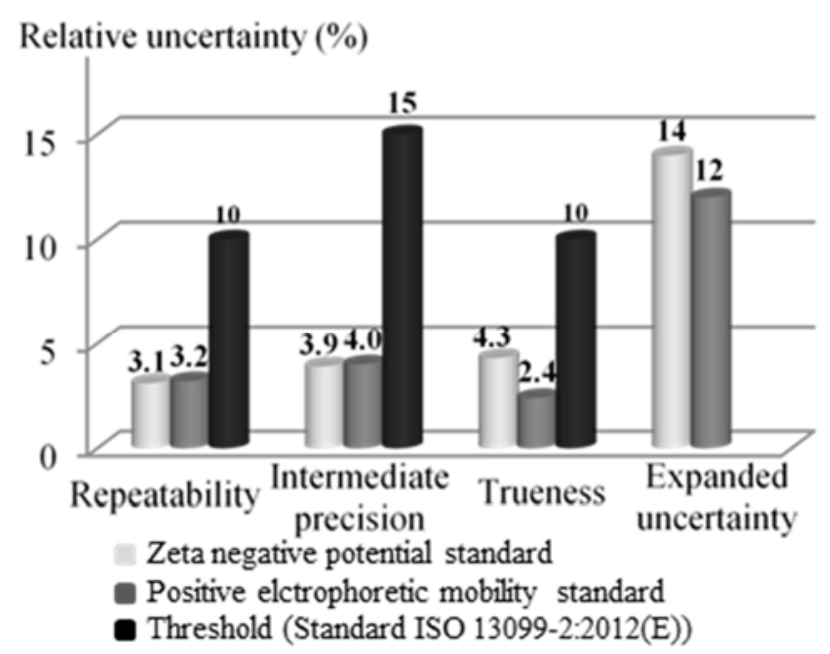

*Corresponding author: Christine Vauthier; UMR CNRS 8612, Institut Galien Paris-Sud, Faculty of Pharmacy Paris-Sud, 5, rue Jean-Baptiste Clément, 92296 Châtenay-Malabry, France E-mail: christine.vauthier@u-psud.fr. Tel.: +33(0)146835603; Fax: +33(0)146835946 


\section{Abstract}

Surface properties of nanomaterials are important characteristics influencing the in vivo fate. Today, the most common parameter considered while characterizing nanomaterial surfaces evaluates their surface charge determining an apparent zeta potential. This zeta potential is deduced from measurement of the electrophoretic mobility of nanomaterials dispersed in aqueous media by well established methods that are described in the standards ISO 13099. Among the different methods, electrophoretic light scattering (ELS) is used in routine in many laboratories, but no validated protocols were proposed so far. This paper was aimed to propose a standardization of a protocol for evaluating zeta potential of nanomaterials by ELS and a methodology to achieve its validation. The robustness, precision and trueness were investigated using reference materials including positive and negative standards. To assess the robustness, experimental factors that could influence results from measurements of zeta potential were considered. These included the batch of measurement cells, the temperature of sample, the type of measurement cells and the analyst giving reliability of protocol for normal usage. Specifics methods of nested designs were developed to investigate robustness and precision and interpret the results using analysis of variance ANOVA. The estimation of the contribution of each factor to the total variance using the estimated mean square values and the equations for expected mean square was used to interpret the ANOVA table. When this method could not be used because of the obtaining of a negative value of the variance, the method based on pooled variances was used to interpret the ANOVA table. The proposed protocol was found robust, accurate and consistent with standard ISO. Uncertainty of the protocol were 14 and $12 \%$ for nanomaterials of negative and positive charges respectively proving reliability of results and approving the validity of the protocol used.

Key words: Nanomaterials, Electrophoretic light scattering, Standardized protocol, Validation, Analysis of variance, Nested design.

\section{Abbreviations}

AFM: Atomic force microscopy

ANOVA: Analysis of variance

AT: Ambient temperature

CRM: Certified reference material

$\mathrm{CV}$ : Coefficient of variation

DLS: Dynamic light scattering

EAS: Electroacoustic spectroscopy

ELS: Electrophoretic light scattering

ERM: European Reference Materials

FFR: Fast field reserval

GUM: Guide to the expression of uncertainty in measurement

IBCA: Isobutylcyanoacrylate

$\mathrm{ICH}$ : International Conference on Harmonisation

of Technical Requirements for Registration of

Pharmaceuticals for Human Use

IP: Intermediate precision
IRMM: Institute for Reference Materials and Measurements

ISO: International Organization for

Standardization

NCL: Nanotechnology Characterization Laboratory

NIST: National Institute of Standards and Technology

PALS: Phase analysis light scattering

PDI: Polydispersity index

PIBCA: Poly(isobutylcyanoacrylate)

r: Repeatability

RM: Reference material

SFR: Slow field reversal

$\mathrm{t}$ : Trueness

XPS: X-ray photoelectron spectroscopy 


\section{Introduction}

Nanomaterials are applied in many applications. In the field of medicine, they are developed as delivery systems for drug administration devices for diagnostic to be used in imaging techniques and theranostic that combines both therapeutics and diagnosis. Surface charge of nanomaterials are determinant for the stability of dispersions while intentionally or non-intentionally introduced in the body. Surface charge of nanomaterials were identified as one of the key characteristics influencing the biodistribution hence the accumulation in define organs within guidances provided by health agencies to evaluate safety of nanomaterials including nanomedicines [1-3]. Information about surface charge of nanomaterial can be accessed from the zeta potential. This parameter cannot be determined experimentally but it can be deduced from the electrophoretic mobility of the nanomaterial thanks to the use of models to make the calculation which ranges of validity are described in the standards ISO [4-6]. It is noteworthy that a zeta potential value deduced from measurements of the electrophoretic mobility of the nanomaterial corresponds to an apparent zeta potential because it is extremely difficult to evaluate the contribution of the surface conductivity and to take it into account in calculations.

Measurements of the electrophoretic mobility of a nanomaterial are performed while an electric field is applied on a dispersion of the nanomaterial in an appropriate dispersion medium. Several methods of measurements are described in the standards ISO. They are classified as methods based on acoustic electrophoresis [5] or on optical electrophoresis [6]. The Electroacoustic Spectroscopy (EAS) being an acoustic electrophoresis method and the Electrophoretic light scattering (ELS) using Phase Analysis Light Scattering (PALS) being optical electrophoretic methods are cited as suitable methods to evaluate zeta potential in a Manual of Policies and Procedures of the Center for Drug Evaluation and Research [3]. Although these techniques are used at various extends in both research and industrial laboratories and zeta potential is considered as one of the key parameters to evaluate when characterizing nanomaterials [1], there is a lack of standardized and validated protocols [7]. The only standardized protocol was proposed by the Nanotechnology Characterization Laboratory (NCL), Frederick, MD, USA [8] based on measurements performed by ELS using PALS. While standardization is intended to propose a protocol that would be suitable to achieve measurements on a wide range of materials within the domain of applications of both the method and the protocol for which it was validated. Validation is needed to establish the performance of the protocol proving that it is sufficiently acceptable, reliable and adequate for intended use using reference material $[9,10]$. Validation enables to estimate expanded uncertainty defined as quantitative expression of the reliability of results and to prove the absence of bias. In general, different parameters are used to investigate the performance of a protocol. The robustness measures the ability of a protocol to 
provide unaffected results by small and deliberate variations in measurement conditions giving its reliability for normal usage [10]. The precision evaluates the closeness of agreement between a series of independent results obtained from measurements performed on the same homogeneous sample using the same protocol depending only on the distribution of random errors and not related to the true value or the specified value i.e. same protocol on identical test items, same laboratory, same analyst, same equipment over short periods for repeatability (intra-day) and longer period for intermediate precision (inter-day) [911]. The trueness involving systematic errors usually expressed in terms of bias evaluates the closeness of agreement between the average value obtained from a large series of results and the value which is accepted either as a conventional true value or an accepted reference value $[9,10]$. Finally, the working range gives the range of measured values for which the reliability of protocol have been proved [10]. Limit of detection, limit of quantification and linearity are also describes in the guidelines Q2(R1) from International Conference on Harmonisation of Technical Requirements for Registration of Pharmaceuticals for Human Use (ICH guidelines Q2(R1)) [10]. These parameters are rather suitable to evaluate performance of quantitative procedures and did not apply in the present case because the application of ELS using PALS to the measurement of electrophoretic mobility is based on first principle and did not required a calibration. The standard ISO [5] recommends to achieve precision i.e. repeatability and intermediate precision and trueness studies using either reference material (RM, material which is sufficiently homogeneous and stable over time and temperature with respect to one or more specified properties and the accepted value has been rigorously proven and determined by several analysts $[5,12]$ ) or certified reference material (CRM, material provided with certificate giving certified value of one or more specified properties and its uncertainty at a defined level of confidence determined by a metrological valid procedure $[5,12])$. It is noteworthy that number of samples required to perform each investigation is not specified in the standard ISO [5].

To our knowledge, no validation of an operating protocol for zeta potential measurement by ELS using PALS and being suitable for many types of nanomaterials using appropriate reference materials with assigned $\mathrm{SI}$ traceable values was published so far.

The aim of the present work was to propose a standardized protocol to evaluate zeta potential of nonconducting nanomaterials dispersed in aqueous media of low conductivity from electrophoretic mobility measured by ELS using PALS. Two standards with positive and negative charges were used to carry out the validation and to evaluate the reliability of the standardized protocol proposed in this work. To this aim, an original methodology was developed for validating the protocol by combining recommendations of the standard ISO [5], the ICH guidelines Q2(R1) [10] and the Guide to the expression of uncertainty in measurement (GUM) [11]. This methodology aimed to provide with precision and trueness as recommended in the standard ISO [5] and robustness that was out of the scoop of the standard ISO but 
that is required for analytical method according to the ICH guidelines Q2(R1) [10]. Factors explored to achieve the robustness of the protocol were the batch of measurement cells, the temperature of sample, the type of measurement cells and the analyst. The precision and the trueness of the protocol were also investigated. Data were interpreted using appropriate analysis of variance ANOVA that were developed in this work. Finally, the protocol was applied to a series of polymer nanoparticles of various compositions and having negative, almost neutral or positive zeta potential.

\section{Materials and methods}

\subsection{Materials}

Millipore water systems were used to obtain either deionized or ultrapure water (MilliQ ${ }^{\circ}$ ).

For zeta potential measurements, disposable cells (DTS 1070 or DTS 1060 from Malvern) were checked for cleanness and absence of scratches. The cells were washed with filtered ultrapure water through a $0.22 \mu \mathrm{m}$ filter (Roth), followed by filtered ethanol (VWR) through a $0.2 \mu \mathrm{m}$ filter (Millipore) and finally filtered ultrapure water again and stored in a dust-free environment until use.

The cells were used only once per sample as recommended by the supplier and the NCL [8].

The standard ISO [5] recommends to use suitable CRM or RM for electrophoretic mobility to perform validation. RM should be sufficiently homogeneous and stable and the accepted electrophoretic mobility value should be rigorously proven. Positive Electrophoretic Mobility Standard named positive standard was purchased from the National Institute of Standards and Technology (NIST). It is noteworthy that it is the only marketed available CRM certified according to electrophoretic mobility. This CRM is a goethite ( $\alpha$ $\mathrm{FeOOH}$ ) dispersion (500 mg. $\mathrm{L}^{-1}$ ) satured with $100 \mu \mathrm{mol} . \mathrm{g}^{-1}$ phosphate dispersed in a sodium perchlorate solution $5.10^{-2}$ mol. $\mathrm{L}^{-1}, \mathrm{pH}$ 2.5. The goethite powder consists of acicular particles with an average dimension of $60 \mathrm{~nm} \times 20 \mathrm{~nm}$. Negative Zeta Potential Transfer Standard named negative standard was supplied by Malvern. This material is controlled against the only available CRM with a certified positive electrophoretic mobility by the supplier (i.e. the CRM also used in the present work). It is classified as a transfer standard and has been referenced to an accepted standard. This standard has a negative zeta potential value. This reference material contains polystyrene latex in aqueous buffer at $\mathrm{pH}$ 9. Further characteristics of these standards provided by the corresponding suppliers are given in Table 1 (see Appendix A for the reference of each standard). To investigate nanomaterials bearing positive charges and nanomaterials bearing negative charges, we chose to work with the only available CRM and the transfer standard even though the accepted value of the latter is given according to zeta potential. 
Table 1. Characteristics of the standard used as provided by suppliers.

\begin{tabular}{lll}
\hline Property & Negative standard* & Positive standard** \\
\hline Electrophoretic mobility $\left(\mu \mathrm{m} . \mathrm{cm}^{*} \mathrm{~V}^{-1} \cdot \mathrm{s}^{-1}\right)$ & - & $2.53 \pm 0.12$ \\
Zeta potential $(\mathrm{mV})$ & $-42 \pm 4.2$ & - \\
Size $(\mathrm{nm})$ & $\mathrm{NS}$ & $60 \times 20$ \\
Operating temperature $\left({ }^{\circ} \mathrm{C}\right)$ & 25 & $20-25$
\end{tabular}

*The accepted value of negative standard is given according to zeta potential and not to electrophoretic mobility. ${ }^{* *}$ Positive standard is certified according to electrophoretic mobility and not to zeta potential. NS: Not specified (no size is given).

For the preparation of polymer nanoparticles decorated with polysaccharides, isobutylcyanoacrylate (IBCA) used as monomer was purchased from Orapi. Dextran (66.7 kDa), dextran sulfate (36 - 50 kDa) and chitosan (Water soluble, $20 \mathrm{kDa}$ ) were purchased from Sigma-Aldrich, ICN Biomediaclas and Amicogen respectively. Cerium (IV) ammonium nitrate was purchased from Fluka. Nitric acid (purity between 61.5 and $65.5 \%$ ) was provided by Prolabo. Sodium hydroxyde (purity $\geq 98 \%$ ) and sodium chloride (purity $\geq 99.5 \%$ ) were purchased from Sigma.

\subsection{Methods}

\subsubsection{Preparation of standards for measurements}

Negative standard. Negative standard was provided in prefilled syringes and was used as supplied. The standard was stored at $4^{\circ} \mathrm{C}$. Syringes were equilibrated at ambient temperature (AT) between 20.0 and $22.5^{\circ} \mathrm{C}$ before use.

Positive standard. Positive standard was provided in bottles and required dilution before measurements. The dilution was performed according to instructions provided by the supplier. The sealed bottle of standard was stored at ambient temperature. All glassware and plasticware used for dilution were meticulously cleaned with filtered ultrapure water with $0.22 \mu \mathrm{m}$ membrane filters (Roth), dried and stored in dust-free environment. Resistance of ultrapure water used for dilutions was checked to be equal to 18 $\mathrm{M} \Omega$ before filtering with $0.22 \mu \mathrm{m}$ membrane filters. Prior to the opening, the bottle of standard was shaked vigorously for $1 \mathrm{~min}$ using wrist action to rehomogeneize the dispersion. An aliquot of $10 \mathrm{~mL}$ was transferred into volumetric flask of $100 \mathrm{~mL}$. Volume was adjusted to the mark with filtered ultrapure water. The dilute dispersion was homogeneized by gently and thoroughly inverting the volumetric flask thirteen times without shaking and transferred to a polypropylene flask rinsed beforehand 5 times with $100 \mathrm{ml}$ of deionised water and then 3 times with $20 \mathrm{~mL}$ of filtered ultrapure water. The dilute dispersion was ultrasonicated (Branson) for $1 \mathrm{~min}$ at $42 \mathrm{~W}$. After cooling to AT between 20 and $25^{\circ} \mathrm{C}$, the pH was measured (Hanna Instruments). If necessary, it was adjusted to $3.5 \pm 0.1$ as recommended by the supplier using filtered nitric acid 0.1 mol. $\mathrm{L}^{-1}$ or hydroxyde sodium $0.1 \mathrm{~mol} . \mathrm{L}^{-1}$ using $0.22 \mu \mathrm{m}$ filter (Millipore). No filtration 
of the obtained dilute standard was required. Final dispersion was translucent bright yellow and no sedimentation was observed. Dilute samples were prepared before use and kept at AT between 20.0 and $22.5^{\circ} \mathrm{C}$ closed to the temperature measurement. After opening, the standard was used over 7 days as recommended by the supplier. The bottle was resealed between sampling and stored at AT.

\subsubsection{Preparation of poly(isobutylcyanoacrylate) nanoparticles decorated with polysaccharide}

Poly(isobutylcyanoacrylate) nanoparticles (PIBCA nanoparticles) decorated with polysaccharide were prepared by redox radical emulsion polymerisation as previously described by Bertholon et al. [13], Chauvierre et al. [14] and Zandanel et al. [15].

Briefly, a polysaccharide (dextran, dextran sulfate or purified chitosan; $0.1356 \mathrm{~g}$ ) was dissolved in $8 \mathrm{~mL}$ of aqueous nitric acid $0.2 \mathrm{~N}$ in a glass tube at $40^{\circ} \mathrm{C}$. Argon bubbling was applied for $10 \mathrm{~min}$ and $2 \mathrm{~mL}$ of a solution of cerium (IV) ammonium nitrate $8.10^{-2} \mathrm{M}$ in aqueous nitric acid $0.2 \mathrm{~N}$ was added followed immediately by $0.5 \mathrm{~mL}$ of IBCA. The polymerization continued for one hour. Milky dispersions of polymer particles were obtained. After cooling down in ice bath, the dispersions were purified by dialysis (Spectra/Por membrane Biotech, molecular weight cutoff of $100000 \mathrm{Da}$, Spectrum Laboratories) twice against $1 \mathrm{~L}$ of deionized water for $30 \mathrm{~min}$, once for 6 hours and the last overnight. The purified dispersions were stored at $4^{\circ} \mathrm{C}$ until use. Nanoparticle size were $241 \pm 10,253 \pm 10$ and $394 \pm 16 \mathrm{~nm}$ with PDI of $0.080 \pm$ $0.008,0.092 \pm 0.019$ and $0.144 \pm 0.052$ for PIBCA nanoparticles decorated with dextran, dextran sulfate and chitosan respectively as determined by dynamic light scattering (DLS).

Three aliquots of $250 \mu \mathrm{L}$ for each dispersion were frozen at $-20^{\circ} \mathrm{C}$ and freeze dried during 24 hours (Alpha 1-2 LD Plus, Bioblock Scientific) for determining the concentration in nanoparticles of the dispersions.

To evaluate zeta potential on unknown samples, sample preparation was based on equilibrium dilution procedure described in the standard ISO [4] for which liquids remain identical between diluted samples i.e. the liquid used in the original dispersion was employed for preparing diluted samples. Only concentration in nanoparticles changed between diluted samples. It is noteworthy that medium of dispersions of tested nanomaterials was water as all dispersions were purified by dialysis against a large volume of ultrapure water. As ultrapure water is not conductive, it was chosen to dilute samples at a final concentration of $\mathrm{NaCl}$ of $1 \mathrm{mM}$. Sodium chloride solutions used to achieve the dilutions were pre-filtered with $0.22 \mu \mathrm{m}$ filter (Roth). 


\subsubsection{Principle of ELS}

Estimation of surface charge and determination of zeta potential of nanomaterials can be performed from electrophoretic mobility measurement. In practice, dispersions of nanomaterials are placed into a measurement cell equipped with a pair of plated-gold electrodes placed at known distance from each other.

Charged particles dispersed in electrolyte solutions are subjected to electrophoresis phenomenon when an electrical field is then applied. They are submitted to two opposing forces, an electrostatic force attracting them towards the electrode of opposite charge and a frictional force due to the viscosity of medium that tends to oppose their migration towards the electrode of opposite charge. When these opposing forces are balanced and equilibrium is reached, charged particles move uniformly at a constant velocity that corresponded to their electrophoretic mobility $\left(\mu_{\mathrm{ep}}\right)$.

Zeta potential, $\zeta$, of dispersed nanoparticles is related to the electrophoretic mobility of the nanomaterials by an extension of the Henry Equation (Eq. (1)).

$\mu_{\mathrm{ep}}=\frac{2 \varepsilon \cdot \zeta \cdot \mathrm{f}(\kappa \mathrm{a})}{3 \eta}$

where $\varepsilon$ is the dielectric constant, $\mathrm{f}(\kappa \mathrm{a})$ is the Henry's function and $\eta$ is the viscosity of the dispersing medium. Assumptions associated with this equation are described in the standard ISO [5]. It is noteworthy that the zeta potential deduced from this equation is not corrected from the surface conductivity hence it corresponds to an apparent zeta potential [16-18]. The standardized protocol developed in this work was designed to be applied to the evaluation of the zeta potential of non-conducting nanomaterials dispersed in aqueous media with a low concentration of electrolytes $\left(10^{-3} \mathrm{M}\right)$. These systems allowed to apply the approximation of Smoluchowski in which the Henry's function takes the value of 1.5 [5].

The validation was performed within the range of application of the model of Smoluchowski where the function $\mathrm{f}(\kappa \mathrm{a})=1.5$.

As stated by the extension of the Henry Equation, other factors may influence electrophoretic mobility. The viscosity of the dispersing medium is required hence the temperature needs to be accurately controlled during the measurement. Variations of temperature during measurements may induce convection movements which can lead to bias in the determination of electrophoretic mobility.

It is noteworthy that capillary walls of the measurement cells may be charged. For instance, single use measurement cells made of polycarbonate have negative charges on the cell wall surface. So nanoparticles 
are subjected to electroosmosis phenomenon leading to electroosmotic mobility. This phenomenon corresponds to the movement of the liquid adjacent to the inner walls of the cells caused by the application of the electrical field. The direction and the velocity of electroosmosis flow depend on the sign and charge magnitude of wall. If there are no other phenomena, the apparent mobility of charged nanomaterials placed in the applied electrical field corresponds to the superimposition of the electrophoretic mobility of the materials and the electroosmotic mobility. In general, the time needed by nanomaterials to reach their terminal electrophoretic mobility is much shorter than that taken to completely established the electroosmotic flow. This was exploited in some measurement instruments to avoid the incidence of the electroosmotic flow. It is noteworthy that nanomaterial may adsorb on the cell wall surface disturbing the establishment of the formation of the electroosmotic flow until the adsorption phenomena has reached its own equilibrium.

Once measurements of the electrophoretic mobility of dispersed nanomaterials can be performed by electrophoretic light scattering with Doppler shifts in scattered light, their zeta potential can be calculated using the extension of the Henry Equation and it also allows the determination of the distribution of electrophoretic mobility hence the distribution of zeta potential of the population of nanomaterials contained in the dispersion. The dispersion of nanomaterials placed in an electric field are illuminated with a coherent light using a Laser source. The frequency of scattered light by the moving of nanomaterials is shifted due to the Doppler effect. Particle electrophoretic mobility distribution can then be determined from the frequency shift distribution. Several marketed measurement instruments use this principle to access measurement of electrophoretic mobility. For instance, the Zetasizer Nano range from Malvern Instruments uses electrophoresis laser scattering with Doppler shifts in combination with M3-PALS [19]. The M3 technology consists in achieving two mobility measurements based on Slow Field Reversal (SFR) and Fast Field Reversal (FFR) measurements. In the case of FFR, the electric field is reversed quickly. The materials reach terminal mobility as the electroosmotic flow is not significant. Thus, the apparent mobility of charged nanoparticles is not affected by the electroosmosis phenomenon and only depends to electrophoresis. The FFR measurement is performed at the centre of measurement cells providing mean zeta potential. In the case of SFR, the electrical field is reversed slowly to avoid polarization of the electrodes. The SFR measurement is carried out to improve resolution of distribution. The PALS technique improves accuracy and sensitivity of electrophoretic mobility measurement i.e. low electrophoretic mobility material measurements and electrophoretic mobility measurements of high conductivity samples can be achieved. PALS uses the same optical setup as ELS with Doppler shifts in scattered light. But, the processing method is different and consists in the analysis of difference phase between a reference laser beam and a laser beam scattered by the nanomaterials measured the scattered angle of $13^{\circ}$ instead of the frequency shift. The measured difference phase is proportional to the nanomaterial electrophoretic mobility. 


\subsubsection{Measurements of the electrophoretic mobility and zeta potential of standards}

The dispersion should not show a specific absorption at the wavelength of the laser source that is mounted in the measurement instrument. Absorption spectra of each standard was monitored within the wavelength range of $190-1100 \mathrm{~nm}$ at $25 \pm 0.1^{\circ} \mathrm{C}$ (Perkin Elmer, Lambda 35 UV-Vis Spectrometer, no smooth).

The zeta potential or the electrophoretic mobility of the nanoparticles was measured at the temperature of measurement, $T_{m}$, of $25^{\circ} \mathrm{C}$ by ELS using a Zetasizer Nano ZS (Malvern) equipped with a laser source (wavelength $633 \mathrm{~nm}$ ) at a scattered angle of $13^{\circ}$. The temperature of measurement, $T_{m}$, was differentiated from the temperature of the sample, $T_{s}$, introduced into the measurement cell. After visual inspection to select only measurement cells with no default (cleaned and well sealed electrodes, absence of scratches on the optical windows of the measurement cell). Measurement cells were filled out with samples according to the procedure given by the supplier. It was checked carefully that no air bubbles were trapped in the measurement cell that could disturb the quality of the electrical field. Measurement cells were used only once as recommended by the supplier. The measurement cell was then placed in the apparatus in the right direction to run measurements. An equilibration time of 300 seconds was chosen in the protocol to let the sample to equilibrate at $T_{\mathrm{m}}$. Measurements conditions of the protocol are given in Table 2. Quality criteria defined for zeta potential measurements are presented in Appendix B. The measurand was the zeta potential or the electrophoretic mobility for the negative and positive standards respectively.

\subsubsection{Investigation of the adsorption of sample on walls of measurement cells}

\subsubsection{Preparation of measurement cells for surface analysis of the inner part}

Measurement cells that were in contact with samples for which an adsorption on the cell surface was suspected were cut to recover the inner parts to perform surface analysis. The cutting method is illustrated in Appendix C. The band-saw that was retained for further analysis was rinsed with a large amount of ultrapure water followed by ethanol and finally water again. All washing solutions were filtered over a filtered membrane (porosity $0.22 \mu \mathrm{m}$ ). All precautions were taken to avoid contamination of the area of interest prior to perform analysis by atomic force microscopy (AFM) or X-ray photoelectron spectroscopy (XPS). 
Table 2. Summary of measurements conditions.

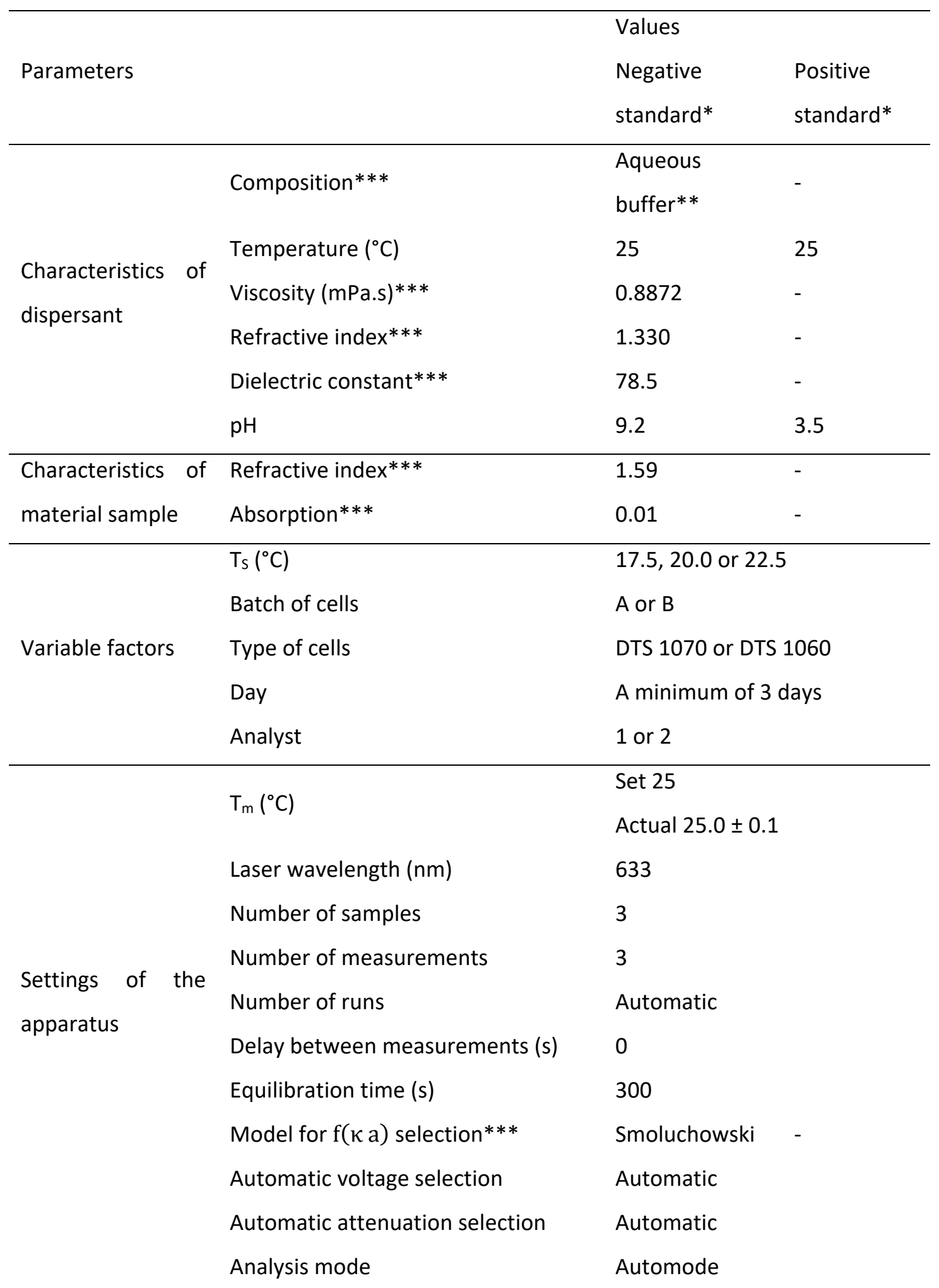

* Negative standard: the measurand was the zeta potential. Positive standard: the measurand was the electrophoretic mobility.

**Unspecified composition.

***Not required for electrophoretic mobility measurement. 


\subsubsection{Surface analysis of the inner part of measurement cells in contact with samples}

Atomic force microscopy. AFM images were collected in air at AT $\left(22^{\circ} \mathrm{C}\right)$ using a commercial Multimode 8 equipped with a NanoScope $V$ controller. The topographical imaging was carried out in Peak Force Tapping mode with n-doped silicon cantilevers (Bruker RTESPA, MPP-12-100). The scan rate was adjusted in the range of $1 \mathrm{~Hz}$ over a selected area in dimension of $1.0 \mu \mathrm{m} \times 1.0 \mu \mathrm{m}$ and $5.0 \mu \mathrm{m} \times 5.0 \mu \mathrm{m}$. The samples $(7 \mathrm{~mm}$ $\mathrm{x} 2 \mathrm{~mm}$ ) were glued on a magnetic disk directly mounted on the top of the AFM scanner and imaged.

$X$-ray photoelectron spectroscopy. Spectra were recorded using a Thermo Scientific K-Alpha XPS instrument fitted with a monochromatized Al X-ray source (1486.6 eV, $400 \mu \mathrm{m}$ spot size). Samples of the measurement cell wall were pressed against a double-sided adhesive tape. Analyses of the surface composition were performed on the face that correspond to the inner walls of the cell. Spectra were recorded using a pass energy set at 50 and $200 \mathrm{eV}$ for the narrow and survey regions, respectively. An electron flood gun was used to compensate for the static charge built up on the insulating surface. The surface composition (in atomic percent) was determined by considering the peak area and the manufacturer's sensitivity factors.

\subsubsection{Validation of the measurement protocol: statistical analysis}

Nested designs and corresponding analysis of variance ANOVA can be used to investigate robustness [20, 21] and intermediate precision [22-31] as described in the standard ISO [32]. The theory is detailed in a previous work in which we suggested a validation of a protocol dedicated to size measurement by DLS [33]. Briefly, ANOVA is used in general to test if one or more factors have an influence on a response variable under the assumption that the variances are homogeneous (e.g., using the Levene's Test) and residuals are independently and normally distributed (e.g. using the Ryan-Joiner's Test). The factors are arranged such as each level of one factor is associated at one level of another factor to generate nested designs [34,35]. From ANOVA table established to interpret nested designs, the influence of studied factors could be investigated by decomposing sources of variability according to two ways. The first approach consists in estimating the variance of each factor from their estimated mean square values according to the usual method described in the literature [33] or the pooled variances method [20]. In a second approach, the pvalue that represents the probability to find the observed, or more extreme, results when the null hypothesis is true is used to test if the response variable varies according to this factor. In this work, nested designs were performed to assess robustness and precision of the proposed protocol. The statistical software package Minitab 16 was used to interpret all designs and evaluate of the effects of the studied factors on the zeta potential and electrophoretic mobility obtained from the application of the protocol [36]. 


\subsubsection{Robustness}

Different measurements of zeta potential and electrophoretic mobility were performed on the negative and positive standards by varying experimental factors that may affect the performance of the method. Critical factors were identified as being able to introduce a bias in the measurement and that were considered as essential to introduce in the validation of a measurement protocol. They included factors related to measurement cells (type and hence the volume of sample introduced in cell, batch of fabrication), $T_{s}$ and the analyst. Regarding $T_{s}$, selected temperatures included the AT. The different conditions used to investigate the robustness of the protocol are summarized in Table 3.

Table 3. Factor levels considering for the robustness study of the protocol for measurements performed.

\begin{tabular}{ccccc}
\hline Day & Analyst & Type of cells* & Batch of cells & $\mathrm{T}_{\mathrm{s}}\left({ }^{\circ} \mathrm{C}\right)$ \\
\hline 1 & 1 & DTS 1070 & A & AT \\
2 & 1 & DTS 1070 & B & AT \\
3 & 1 & DTS 1070 & C & $17.5^{* *}$ \\
4 & 1 & DTS 1070 & C & $20.0^{* *}$ \\
5 & 1 & DTS 1070 & C & $22.5^{* *}$ \\
6 & 1 & DTS 1060 & D & AT \\
7 & 2 & DTS 1070 & E & AT \\
\hline
\end{tabular}

*Volume for DTS $1070=800 \mu \mathrm{L}$. Volume for DTS $1060=950 \mu \mathrm{L}$.

**Samples were incubated before analysis at $\mathrm{T}_{\mathrm{s}}$ for 10 minutes.

AT: Ambient temperature

The robustness study was studied step by step in the following order: batch of cells (for range of temperature chosen at the previous step), Ts, type of cells and analyst. Zeta potential and electrophoretic mobility measurements were performed on the negative standard and on the positive standard respectively (characteristics were given in Table 1). All measurements were performed in triplicates as indicated in measurement conditions given in Table 2 and included in the protocol. They corresponded to Rep. 1, Rep. 2 and Rep. 3 in the Fig. 1.

The general nested design for the study of each factor is given in Fig. 1. Three measurement cells were used per level of factor and each sample filled in a measurement cell was analyzed three times successively once placed in the measurement instrument. The total variability of the results of this design can be attributed to the following levels of variability:

- between levels of factor variability,

- between cells (or samples) variability analyzed within the same level of factor [within levels of factor],

- between replicates variability [within cells]. 
The corresponding ANOVA table is given in Appendix D. The values of $a, b$ and $n$ are given in Table 4 . Considerations of the factor as random or fixed are also indicated in Table 4. The same design was used for the study of $T_{s}$ (three samples per temperature, fixed factor), the batch of measurement cells (three samples per batch, random factor), the type of measurement cells (three samples per type, fixed factor) and the analyst (three samples per analyst, random factor). The corresponding ANOVA tables were similar (except the degree of freedom number for the upper-level factor).

a

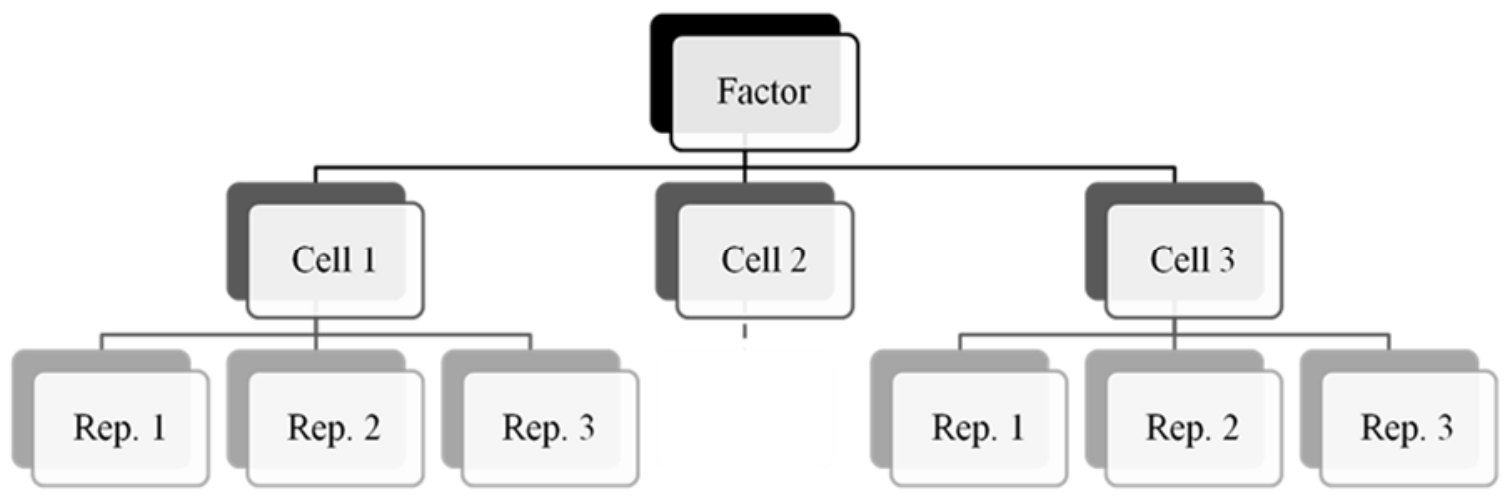

Fig. 1. General design for nested ANOVA in which the factors batch of cells, cells and replicates were studied. Symbols $a, b$ and $n$ represented the number of levels of a nested factor within the factor above ranked. (Rep.: Replicate).

Table 4. Classification of factors and number of levels of each factor.

\begin{tabular}{ccccc}
\hline Level & Ts & $\begin{array}{c}\text { Batch of } \\
\text { measurement cells }\end{array}$ & $\begin{array}{c}\text { Type of } \\
\text { measurement cells }\end{array}$ & Analyst \\
\hline a & 3 (fixed) & 2 (random) & 2 (fixed) & 2 (random) \\
b & 3 (random) & 3 (random) & 3 (random) & 3 (random) \\
n & 3 (random) & 3 (random) & 3 (random) & 3 (random) \\
\hline
\end{tabular}

\subsubsection{Precision}

The evaluation of the precision of a given protocol required investigations about the repeatability of measurements performed with the same method on identical measurement items in the same laboratory by the same analyst, using the same equipment and over a short time interval and following the same protocol. Considering a single instrument, analyst and laboratory allowed to evaluate the intermediate precision. The repeatability and the intermediate precision were respectively evaluated from measurements on the negative and positive standards performed within day and over several days.

The general nested design given in Fig. 1 was applied to analyze the data considering as factor the moment that the measurements were performed. For the analysis of the repeatability, it was considered over the 
same day and for the intermediate precision measurements were taken over 3 different days. Three samples using zeta measurement cells were used per day. Each sample filled in a measurement cell was analyzed three times successively. Numbers represented the levels of the nested factors were 3,3 and 3 for $\mathrm{a}, \mathrm{b}$ and $\mathrm{n}$ respectively. All factors were considered as random. The total variability of the results of this nested design can be attributed to the following levels of variability:

- between days variability,

- between cells (or samples) variability analyzed on the same day [within days],

- between replicates variability [within cells].

The relative standard uncertainty of repeatability, $u_{r}$, was estimated using Eq. (2) and the one of intermediate precision, $\mathrm{u}_{\mathrm{ip}}$, according to Eq. (3) from the dataset. Variances were calculated using nested ANOVA.

$\mathrm{u}_{\mathrm{r}}=\frac{\mathrm{s}_{\text {replicates }}}{\mathrm{C}_{\mathrm{m}}}$

where $\mathrm{s}_{\text {replicates }}$ was the standard deviation of replicates within samples and $\mathrm{C}_{\mathrm{m}}$ was the overall average value.

$\mathrm{u}_{\mathrm{ip}}=\frac{\mathrm{s}_{\mathrm{among} \text { days }}}{\mathrm{C}_{\mathrm{m}}}$

where $\mathrm{s}_{\text {among days }}$ was the standard deviation among days.

\subsubsection{Trueness}

The approach described in the European Reference Materials (ERM) Application Note 1 was used to evaluate the trueness of the protocol that allowed to evaluate if there was significant difference between results provided from the measurements and the certified value of a certified standard [37]. Briefly, the absolute bias, $\Delta_{\mathrm{m}}$, corresponding to the difference between the mean measured value, $\mathrm{C}_{\mathrm{m}}$, and the certified value, $\mathrm{C}_{\mathrm{CRM}}$, as it expanded uncertainty, $\mathrm{U}_{\Delta}$, were calculated. Then, $\Delta_{\mathrm{m}}$ was compared to $\mathrm{U}_{\Delta}$. If $\Delta_{\mathrm{m}} \leq \mathrm{U}_{\Delta}$, it meant that there was no significant difference between the measurement value and the certified value. In this case, the relative standard uncertainty of trueness, $u_{t}$, was estimated from the dataset according to Eq. (4). 
$\mathrm{u}_{\mathrm{t}}=\frac{\mathrm{u}_{\Delta}}{\mathrm{C}_{\mathrm{m}}}$

where $\mathrm{u}_{\Delta}$ is the uncertainty of the bias.

The detailed calculations are given in Appendix E.

\subsubsection{Measurement uncertainty}

The uncertainty caused by variations of $T_{m}$ hence of the viscosity of the dispersing medium were assumed to be included in the standard uncertainties of intermediate precision and trueness.

The combined uncertainty, $u_{c}\left(\right.$ zeta or $\left.\mu_{e p}\right)$, on measurements of zeta potential was estimated by combining the standard uncertainties of type A from repeatability, $u_{r}$, intermediate precision, $u_{i p}$, and trueness, $u_{t}$, according to Eq. (5). As the method of measurement does not require calibration, any type $B$ uncertainty from its contributions was added.

$\mathrm{u}_{\mathrm{c}}\left(\right.$ zeta or $\left.\mu_{\mathrm{ep}}\right)=\sqrt{\mathrm{u}_{\mathrm{r}}^{2}+\mathrm{u}_{\mathrm{ip}}^{2}+\mathrm{u}_{\mathrm{t}}^{2}}$

Then, the expanded uncertainty, $U\left(\right.$ zeta or $\left.\mu_{e p}\right)$, was determined using Eq. (6) for a confidence level of 95 $\%$.

$\mathrm{U}\left(\right.$ zeta or $\left.\mu_{\mathrm{ep}}\right)=\mathrm{t}_{1-\alpha}(v) \cdot \mathrm{u}_{\mathrm{c}}\left(\right.$ zeta or $\left.\mu_{\mathrm{ep}}\right)$

where $t_{1-\alpha}(v)$ was the t-value for Student's t-distribution of the measured values for a given number of freedom degree $v$ and a confidence level $\alpha$ of $95 \%$.

\subsection{Application: Characterization of polymer nanoparticles}

Dispersion of nanoparticles were diluted in filtered aqueous solution of sodium chloride $1 \mathrm{mM}$. Then, the measurements were performed using disposable cells DTS 1070 after 300 seconds of equilibration with the experimental protocol of measurements described in Table 2. The application of the method implies several requirements on the general characteristics of the samples. Visible spectra of dispersions were acquired at $25^{\circ} \mathrm{C}$ with a spectrophotometer as described in $\S 2.2 .4$. An optimal concentration of the dispersion should be found to achieve measurements. The balance at the optimal concentration is a 
compromise between low levels of scattering light (minimum count rate of scattered light being equal to 20 kcps to perform zeta potential measurements) and multiple scattering. The minimum concentration required will depend on difference in refractive index properties of particles and the medium and size particles. In the case of large particles, it generates more scattered light. Lower concentrations may be used. The laser beam needs to penetrate across the sample. The laser beam will be attenuated by particles and the detected scattered light will be reduced if sample concentration is too high. For the compensation of this phenomena, attenuation will be adjusted for the detector to receive more scattered light [38]. Dilutions of purified suspension were prepared in filtered aqueous solution of sodium chloride $1 \mathrm{mM}$ in the range 0.0001 to $15 \mathrm{mg} \cdot \mathrm{mL}^{-1}$ for PIBCA nanoparticles decorated with dextran and those decorated with dextran sulfate and in the range 0.0001 to $25 \mathrm{mg} \cdot \mathrm{mL}^{-1}$ for PIBCA nanoparticles decorated with chitosan. These dispersions were measured with all parameters set in the validated protocol. Position of attenuator and zeta potential were plotted against the concentration of the dilution used.

After identification of the optimal concentration, qualified measures were performed using the following sequence of measurements: 1 sample of standard, samples of nanoparticles at optimal concentration and 1 sample of standard again. Provided that results obtained for the standard agreed with specification given on the certificate, results for the sample were expressed as the mean value \pm the expanded uncertainty of the negative and positive standards for nanoparticles bearing negative and positive charges respectively.

\section{Results and discussion}

\subsection{Preliminary control to validation}

\subsubsection{Spectral characteristics of the standards}

Visible absorption spectrum of each standard was monitored. Both standards showed typical turbidity curves with no absorbance band at the wavelength of the laser source mounted in the zeta potential measurement instrument (Appendix F).

\subsubsection{Conditions for the preparation of the cells with the positive standard}

The provider of the positive standard, the NIST, raises attention to users that it has tendency to adhere on surfaces including those of measurement cells. It suggested that measurement cells should be preconditioned with standard for $1 \mathrm{~min}$ before introducing fresh standard to perform the analysis. As preliminary assays, it was checked that this preconditioning time of $1 \mathrm{~min}$ was suitable with the measurement cells used in this study for electrophoretic mobility measurements. Times used to preconditioned the cells were 1, 5, 10 and 20 min. Results are shown in Table 5. 
Table 5. Average electrophoretic mobility obtained for different preconditioning time of measurement cell with the positive standard.

\begin{tabular}{ccc}
\hline Conditioning time $(\mathrm{min})$ & $\begin{array}{c}\text { Average electrophoretic } \\
\text { mobility }\left(\mu \mathrm{m} \cdot \mathrm{cm} \cdot \mathrm{V}^{-1} \cdot \mathrm{s}^{-1}\right)^{*}\end{array}$ & Decision \\
\hline 1 & $2.02^{* *}$ & Rejected value \\
5 & $2.36^{* *}$ & Rejected value \\
10 & $\mathbf{2 . 4 8}$ & Accepted value \\
20 & $\mathbf{2 . 6 0}$ & Accepted value
\end{tabular}

*Reference value: $2.53 \pm 0.12 \mu \mathrm{m} . \mathrm{cm} . \mathrm{V}^{-1} \cdot \mathrm{s}^{-1}$.

**Out of the specification.

Bold: Within the specification.

The electrophoretic mobility average values obtained with cells that were preconditioned times for 1 and 5 min were out of the specifications while using a longer time, the measured values could be accepted. It seemed that the shortest times were not sufficient to reach a saturation of the measurement cells by adsorption of the goethite particles on the measurement cell walls. The equilibrium of adsorption required $10 \mathrm{~min}$ providing with values of the measured electrophoretic mobility agreeing with that of the specification given for standard. All measurements were then done after $10 \mathrm{~min}$ of preconditioning of the measurement cell.

It is noteworthy that a depot of a yellow film remained on the measurement cell wall after emptying and extensive washing of the cells with water.

AFM analysis was performed on pristine and positive standard contaminated cell surfaces. Clusters of particles appeared on walls of cells having been in contact with the positive standard (Fig. 2 (b) and (d)) while no images of such material could be detected at the same scale of observation on the pristine cell (Fig. 2 (f)). The positive standard contaminated cell surface present particle clusters which size were estimated around $50-70 \mathrm{~nm}$. This size range was consistent with that of the particles contained in the positive standard as indicated on the certificate of analysis $(60 \mathrm{~nm} \times 20 \mathrm{~nm})$.

XPS analysis of the pristine and positive standard contaminated cell surfaces showed spectra given in Fig. 3 . Full spectra were shown in Fig. 3 (a) and (b) and the narrow O1s regions were displayed in Fig. 3 (c) and (d) for the pristine and the sample contaminated cell surfaces respectively. The $\mathrm{C} 1 \mathrm{~s}$ and $\mathrm{O} 1 \mathrm{~s}$ were centred at 285 and $533 \mathrm{eV}$, respectively. C1s narrow region was inserted in Fig. 3 (a) and exhibited three main components: $\mathrm{C} / \mathrm{C}-\mathrm{H}, \mathrm{C}-\mathrm{O}$ and $\mathrm{O}-\mathrm{C}(\mathrm{O})-\mathrm{O}$ that can be accounted for the polycarbonate nature of the cell material. On the positive standard contaminated cell surface, a doublet appeared at $710-730$ eV (Fig. 3 (b)). This was attributed to Fe2p clearly indicating that the cell surface in contact with the positive standard was contaminated with iron oxide. 

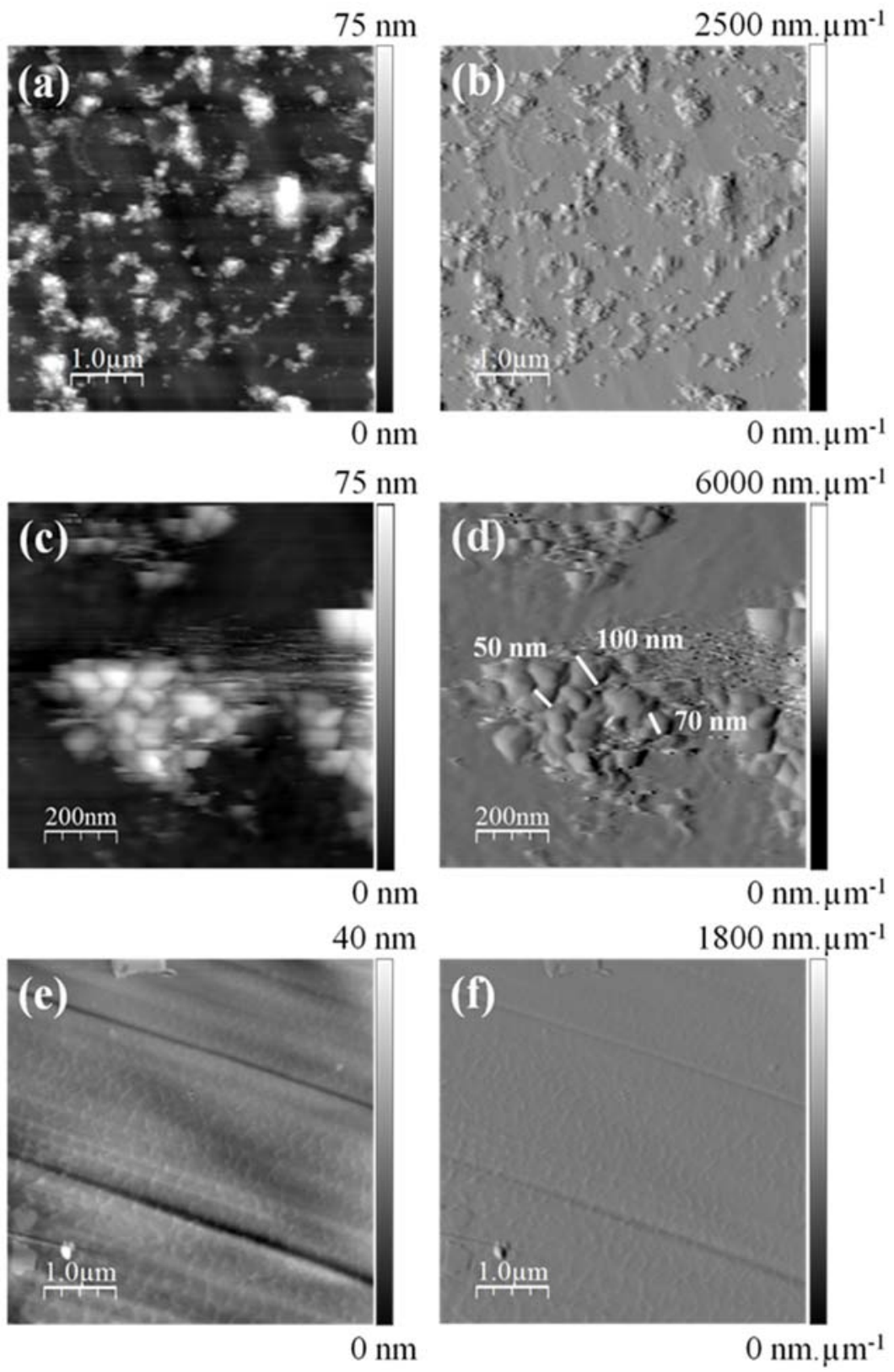

$15 \mathrm{~nm}$

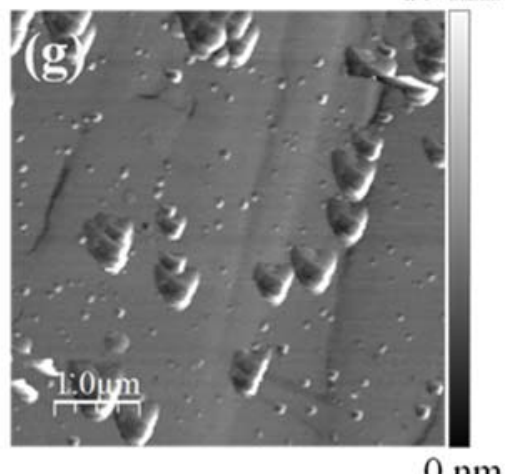

Fig. 2. AFM images. Positive standard contaminated cell surface at $5.0 \mu \mathrm{m} \times 5.0 \mu \mathrm{m}$ : (a) Topography and (b) Derivate. Positive standard contaminated cell surface at $1.0 \mu \mathrm{m} \times 1.0 \mu \mathrm{m}$ : (c) Topography and (d) Derivate. Pristine cell surface at $5.0 \mu \mathrm{m} \times 5.0 \mu \mathrm{m}$ : (e) Topography and (f) Derivate. Cell surface after contact with PIBCA nanoparticles decorated with chitosan at $5.0 \mu \mathrm{m} \times 5.0 \mu \mathrm{m}$ : $(\mathrm{g})$ Topography. Derivative of each topography image is given to exacerbate reliefs except for PIBCA nanoparticles decorated with chitosan for which the outlines of topography image was straight. 

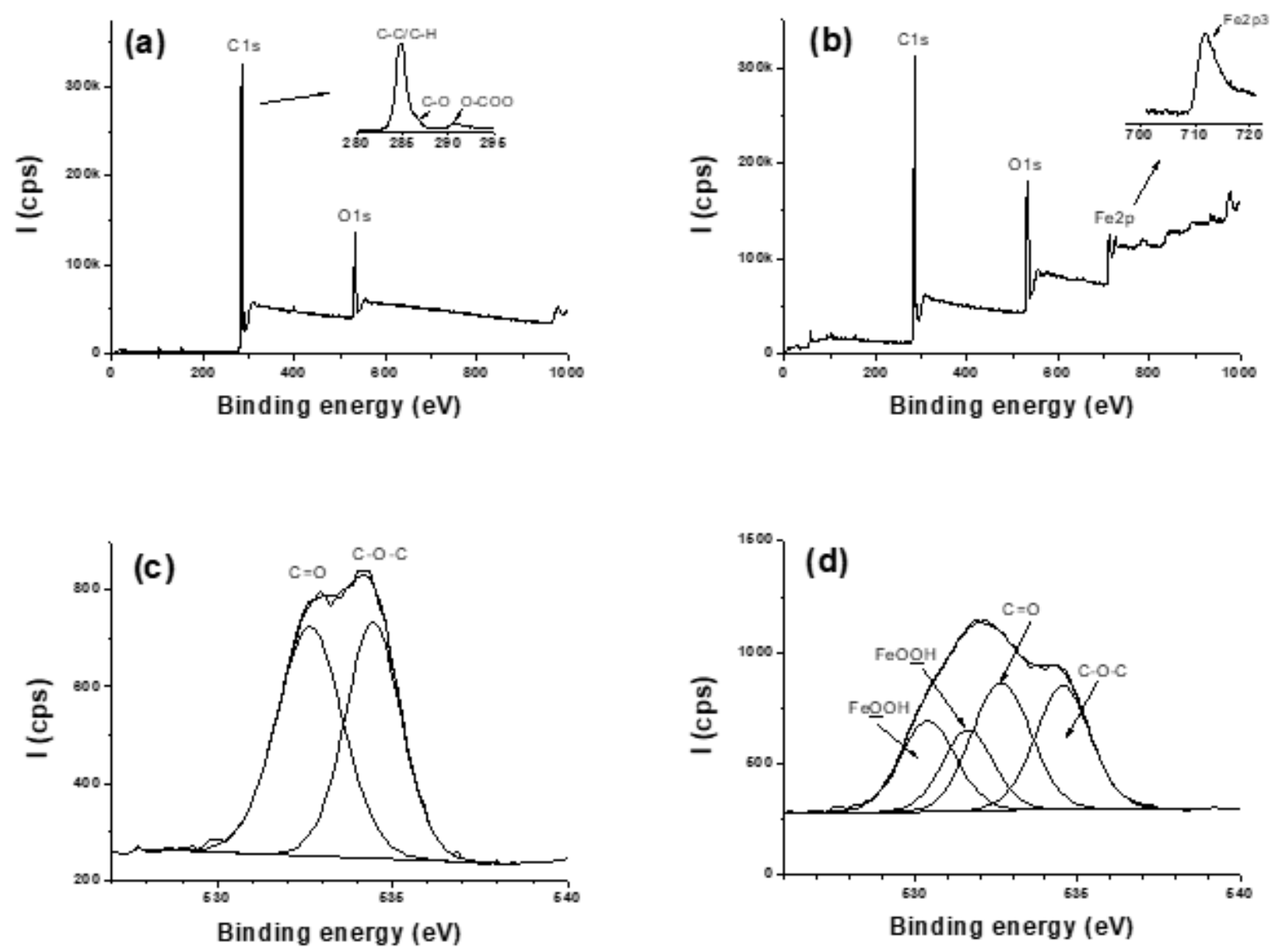

Fig. 3. XPS spectra obtained from the analysis of pristine and positive standard contaminated cell surfaces: Survey $(a, b)$ and $01 s(c, d)$ regions from pristine $(a, c)$ and positive standard contaminated $(b, d)$ cell surfaces. The narrow C1s region was shown in insert for pristine while same shape was observed for both samples.

The 01 s regions (Fig. 3 (c) and (d)) have 2 and 4 components for the pristine and the positive standard contaminated cell surfaces, respectively. The components centered at 532.6 and $534.6 \mathrm{eV}$ were assigned to $\mathrm{C}=\mathrm{O}$ and $\mathrm{C}-\mathrm{O}$, respectively. The additional components displayed in Fig. 3 (d) were assigned to Fe-O (530.4 $\mathrm{eV})$ and $\mathrm{OH}(531.6 \mathrm{eV}$ ) from $\mathrm{FeOOH}$ contaminating the cell wall surface. The O1s binding energy value for the $\mathrm{OH}$ component from $\mathrm{FeOOH}$ was in line with that previously reported by the group of Sherwood et al. at $531.7 \mathrm{eV}$ [39]. The actual binding energy for $\mathrm{O} 1 \mathrm{~s}$ from $\mathrm{Fe}-\mathrm{O}$ in $\mathrm{FeOOH}$ was $530.4 \mathrm{eV}$, higher from that reported previously. The Fe2p3/2 peak was found to be centred at $\sim 711.7 \mathrm{eV}$ matching the value reported elsewhere (711.5 eV) [39]. The surface compositions were given for both type of samples in Table 6. The $\mathrm{O} / \mathrm{C}$ ratio increased from 0.16 to 0.32 from the pristine to the positive standard contaminated cell surfaces. The increase of the $\mathrm{O} / \mathrm{C}$ ratio found for the measurement cell surface contaminated with the positive standard was consistent with a contamination by iron oxide that brought additional atoms of oxygen and no additional carbon atoms. 
Table 6. Composition of the surface of measurement cells as determined by XPS.

\begin{tabular}{cccc}
\hline Type of cell & Name & Atomic percentage (\%) & O/C ratio \\
\hline Pristine & C1s & C 86.1 & 0.16 \\
& O1s & O 14.0 & \\
\hline \multirow{2}{*}{ Positive standard contaminated } & C1s & C 74.6 & 0.32 \\
& Fe2p3 & O 23.7 & \\
\hline
\end{tabular}

As confirmed from AFM and XPS, the positive standard strongly absorbs on measurement cells consistently with awareness raised by the supplier. According to these preliminary experiments, the time required to condition the cells for accurate measurements of the positive standard was a minimum of $10 \mathrm{~min}$.

\subsubsection{Selection of the operation mode for zeta potential measurement}

The protocol of measurement of zeta potential suggested for validation was expected to be applicable on a wide range of nanomaterials. To this aim, the Automode analysis model was selected from the recommendation of the provider of the measurement instrument [40]. Using this setting, the apparatus choose the analysis model depending on the conductivity of the medium in which materials are dispersed and that is measured by the instrument. Below a conductivity of $5 \mathrm{mS} . \mathrm{cm}^{-1}$, measurements are performed with the General Purpose analysis model where as above $5 \mathrm{mS} . \mathrm{cm}^{-1}$, the instrument performed the analysis using a Monomodal analysis model. The conductivity measured for the negative and positive standards

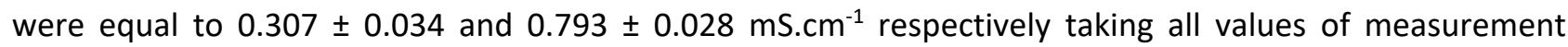
performed for the evaluation of robustness except the series for the investigation of $T_{s} 17.5^{\circ} \mathrm{C}$ and the evaluation of precision. It is noteworthy that for all these measurements, the instruments selected the General Purpose analysis model to perform analysis. Hence the validation of the protocol was achieved on this model.

\subsubsection{Choice of the standards}

According to the standard ISO [5], reference material or certified reference material could be used to perform the validation of a protocol of zeta potential measurement provided that the absolute value of measured electrophoretic mobility of the standard is higher than $2 \mu \mathrm{m} \cdot \mathrm{cm} \cdot \mathrm{V}^{-1} \cdot \mathrm{s}^{-1}$. Even though specification of negative standard was given as zeta potential value, it was verified that this condition was achieved for all measurements. For positive standard, this condition was met in all cases. 


\subsection{Validation}

\subsubsection{Robustness}

\subsubsection{Study of the influence of batch of measurement cells}

The influence of the batch of measurement cells was determined from measurements performed on each standard over two batches of measurement cells. This study was achieved on the most recent reference of measurement cells DTS 1070 marketed by the supplier of the instrument. The normally distribution of residuals and homogeneity of variances were not rejected (see Appendix G, Part 1). The ANOVA executed to interpret the design is shown in Appendix G, Part 2 for both standards.

Results from the calculations of the relative standard uncertainties of the factors batch of measurement cells, $\mathrm{u}_{\text {batch }}$, cell, $\mathrm{u}_{\text {cell }}$, and replicate, $\mathrm{u}_{\text {replicate }}$, are given in Table 7 for both standards.

Table 7. Relative standard uncertainty, $u(\%)$ for the negative and positive standards.

\begin{tabular}{ccc}
\hline Source of variation & Negative standard* & Positive standard** \\
\hline Among batches & $\mathrm{u}_{\text {batch }}=0.7$ & $\mathrm{u}_{\mathrm{batch}}=2.0$ \\
& $(\mathrm{p}>0.05)$ & $(\mathrm{p}>0.05)$ \\
Cells within batches & $\mathrm{u}_{\text {cell }}=2.3$ & $\mathrm{u}_{\text {cell }}=0.8$ \\
Replicates within cells & $(p>0.05)$ & $(p>0.05)$ \\
& $\mathrm{u}_{\text {replicate }}=2.6$ & $\mathrm{u}_{\text {replicate }}=3.2$ \\
\hline
\end{tabular}

* Determined thanks to the pooled variances method.

** Determined thanks to the usual method.

In the case of the positive standard, the usual method provided positive variances allowing to determine standard deviation and relative standard uncertainty. Conversely, this approach that provided negative variances did not permit further analysis of the results in the case of the negative standard, because the factor batch of cells had a smaller influence than the factor placed one rank below in the design i.e. the cell. An approach based on pooled variances analysis was then investigated.

The relative standard uncertainty of the factor batch of cells was equal to 0.7 and $2.0 \%$ for the negative and positive standards respectively. The $p$-value related to this parameter $(p>0.05)$ showed that there was no difference between the zeta potential or electrophoretic mobility measurements made with different batches of cells DTS 1070 whatever the charge of the particles either positive or negative. 


\subsubsection{Study of the influence of the temperature of the sample}

The influence of the temperature of the sample, $T_{s}$, was investigated from measurements performed on each standard over three temperatures of the sample. For both standards, results obtained for all $T_{s}$ tested were presented in Appendix $\mathrm{H}$, Part 1. For the negative standard at $\mathrm{T}_{\mathrm{s}} 17.5^{\circ} \mathrm{C}$, the results were out of specification for the sample 2. The mean count rate was low and equal to 23.9 and $29.4 \mathrm{kcps}$ for the second and third measurements of the sample 3 respectively. Moreover, the zeta potential quality report was unsuccessful for the first measurement of the sample 2. For the positive standard at $T_{s} 17.5^{\circ} \mathrm{C}$, the results for the samples 2 and 3 were out of specification. The difference between $T_{s}$ and $T_{m}$ was too high creating measurement artifacts by degassing of the sample. $\mathrm{T}_{\mathrm{s}}$ taken at $17.5^{\circ} \mathrm{C}$ was therefore considered as not suitable for measurements performed at $25^{\circ} \mathrm{C}$ and was rejected. The difference between $T_{s}$ and $T_{m}$ should be reduced. Results obtained with measurements performed with samples at 20.0 and $22.5^{\circ} \mathrm{C}$ were all acceptable and were used for further analysis. As a result, the levels $a, b$ and $n$ of the factors $T_{s}$, sample and replicate from the design were 2, 3 and 3 respectively. The normally of the residual distribution and the homogeneity of variances were validated (see Appendix $\mathrm{H}$, Part 2). The ANOVA performed to interpret the design is shown in Appendix $\mathrm{H}$, Part 3 for both standards.

Positive values of the variance were obtained permitting to continue the analysis of the data based on the usual method (Table 8).

Table 8. Relative standard uncertainty, $\mathrm{u}(\%)$ for the negative and positive standards.

\begin{tabular}{ccc}
\hline Source of variation & Negative standard* & Positive standard* \\
\hline Among $\mathrm{T}_{\mathrm{s}}$ & $\mathrm{u}_{\text {temperature }}=2.1$ & $\mathrm{u}_{\text {temperature }}=0.9$ \\
& $(p>0.05)$ & $(p>0.05)$ \\
Cells within $\mathrm{T}_{\mathrm{s}}$ & $\mathrm{u}_{\text {cell }}=1.6$ & $\mathrm{u}_{\text {cell }}=0.5$ \\
Replicates within cells & $(p>0.05)$ & $(p>0.05)$ \\
& $\mathrm{u}_{\text {replicate }}=3.0$ & $\mathrm{u}_{\text {replicate }}=3.7$ \\
\hline
\end{tabular}

*Determined thanks to the usual method.

The relative standard uncertainty of the factor $\mathrm{T}_{\mathrm{s}}$ was equal to 2.1 and $0.9 \%$ for the negative and positive standard respectively. The p-value associated to the factor was greater than 0.05 for both standards showing that there was no statistical difference between zeta potential or electrophoretic mobility measurements made at $\Delta \mathrm{T}=-2.5^{\circ} \mathrm{C}$ and those made at $\Delta \mathrm{T}=-5^{\circ} \mathrm{C}$ for $\mathrm{T}_{\mathrm{m}} 25^{\circ} \mathrm{C}, \Delta \mathrm{T}$ representing the difference between $T_{s}$ and $T_{m}$. As already mentioned, results obtained for $\Delta T=-7.5^{\circ} \mathrm{C}$ were out of 
specification and were not further considered. So, preparing samples at a temperature closed to $T_{m}$ is paramount to obtain reliable results of electrophoretic mobility and zeta potential measurements.

\subsubsection{Study of the influence of the type of cells}

Two references of measurement cells were available on the market. So, the validation of the protocol included the investigation of the influence of the type of cells on the results of measurements performed on the two standards. The normality of residual distribution and the homogeneity of variances were not rejected (see Appendix I, Part 1). Results from the statistical analysis of the measurements were summarized in Appendix I, Part 2 for both standards.

Determination of the variance with the usual method provided with negative values that did not permit to further analyze the results for both standards. The negative value for the factor cell can be explained because this factor had a smaller influence than the factor replicate ranked below in the nested design used to analyze the data. In addition, the estimated variance for the factor type of measurement cells was negative for both standards. This approach could not be used to analyze the data of measurements provided both standards. The results were then analyzed with the method based on pooled variances (Table 9).

Table 9. Relative standard uncertainty, $\mathrm{u}(\%)$ for the negative and positive standards.

\begin{tabular}{ccc}
\hline Source of variation & Negative standard* & Positive standard* \\
\hline Among types & $\mathrm{u}_{\text {type }}=0.7$ & $\mathrm{u}_{\text {type }}=0.9$ \\
& $(p>0.05)$ & $(p>0.05)$ \\
Cells within types & $\mathrm{u}_{\text {cell }}=1.4$ & $\mathrm{u}_{\text {cell }}=1.3$ \\
& $(p>0.05)$ & $(p>0.05)$ \\
Replicates within cells & $\mathrm{u}_{\text {replicate }}=2.8$ & $\mathrm{u}_{\text {replicate }}=3.7$
\end{tabular}

*Determined thanks to the pooled variances method.

In this case, the relative standard uncertainties of the factor type of measurement cells could be determined. They were found equal to 0.7 and $0.9 \%$ for the negative and positive standards respectively. The $p$-value related to this parameter $(p>0.05)$ showed that there was no statistical difference between the zeta potential and electrophoretic mobility measured with either a DTS 1070 cell or a DTS 1060 cell. The volume of sample filling the measurement cells had not influence on the measurement provided that the cells were filled out according to the instructions given by the supplier with all the cares mentioned in the Materials and methods section (see § 2.1) and Appendix B. 


\subsubsection{Study of the influence of analyst}

Even very detailed protocols are subjected to the interpretation by analyst that in turn may provide with a source of variability of results on measurements performed by different analysts. To account for this possible source of influence in the validation procedure, measurements of the two standards were performed by two independent analysts. The normally distribution of residuals and the homogeneity of variance were checked (see Appendix J, Part 1). The ANOVA established to interpret this design are presented in Appendix J, Part 2 for both standards.

Negative values of the variance were obtained by applying the usual method for the analysis of data that could be explained by the fact that the factor cell had a smaller influence that the factor replicate located below in the design. Thus, the value of the mean square of the factor cell was less than the factor replicate. In the case of the positive standard, the variance associated with the factor analyst was also negative. In any case, the usual approach could not be further used to interpret the ANOVA table. The approach based on pooled variances was then investigated (Table 10).

Table 10. Relative standard uncertainty, $\mathrm{u}(\%)$ for the negative and positive standards.

\begin{tabular}{ccc}
\hline Source of variation & Negative standard* & Positive standard* \\
\hline Among analysts & $\mathrm{u}_{\text {analyst }}=1.2$ & $\mathrm{u}_{\text {analyst }}=0.9$ \\
Cells within analysts & $(p>0.05)$ & $(p>0.05)$ \\
Replicates within cells & $\mathrm{u}_{\text {cell }}=1.0$ & $\mathrm{u}_{\text {cell }}=1.3$ \\
& $(p>0.05)$ & $(p>0.05)$ \\
\hline
\end{tabular}

*Determined thanks to the pooled variances method.

This last approach provided with the relative standard uncertainties of the factor analyst equal to 1.2 and $0.9 \%$ for the negative and positive standards respectively. Being greater than 0.05 , the p-value showed that there was no statistical difference between the measurements made by different analysts applying the protocol of measurement described in this study and taking care of all recommendations given to prepare samples, select, prepare and fill out measurement cells.

\subsubsection{Precision}

The repeatability and the intermediate precision were evaluated from measurements carried out on each standard over 3 days. The normally of residual distribution and homogeneity of variances were validated 
(see Appendix K, Part 1). The ANOVA tables used for the interpretation of measurements performed on the two standards are presented in Appendix K, Part 2 for both standards.

The variance associated to the factor cell was negative considering the analysis of data collected from measurements performed on the negative standard using the usual method. The factor cell had a smaller influence than the factor replicate ranked above in the nested design used. Thus, the approach based on pooled variances was considered and results are summarized in Table 11. In contrast, variances obtained from the usual method of analysis of the data were positive allowing to determine relative standard uncertainty in the case of the positive standard (Table 11).

Table 11. Relative standard uncertainty, $\mathrm{u}(\%)$ for the negative and positive standards.

\begin{tabular}{ccc}
\hline Source of variation & Negative standard* & Positive standard** \\
\hline Among days & $\mathrm{u}_{\mathrm{ip}}=3.9$ & $\mathrm{u}_{\mathrm{ip}}=.0$ \\
Cells within days & $\mathrm{u}_{\text {cell }}=1.5$ & $\mathrm{u}_{\text {cell }}=2.8$ \\
Replicates within cells & $\mathrm{u}_{\mathrm{r}}=3.1$ & $\mathrm{u}_{\mathrm{r}}=3.2$ \\
\hline
\end{tabular}

*Determined thanks to the pooled variances method. ${ }^{* *}$ Determined thanks to the usual method.

According to the standard ISO [5], the relative standard uncertainties of repeatability and intermediate precision for the mean electrophoretic mobility values for a reference material must be lower than 10 and $15 \%$ respectively. The thresholds provided by the standard ISO [5] for the standard uncertainties of repeatability and intermediate precision of electrophoretic mobility values were considered as the limit values for the relative standard uncertainties of repeatability and intermediate precision of zeta potential values for the negative standard used in the present study. The standard uncertainties of repeatability and intermediate precision varied from 3.1 to 3.2 and 3.9 to 4.0 considering both standards. These values were lower than the thresholds provided by the standard ISO [5]. Thus, the proposed protocol is precise under repeatability conditions and defined intermediate precision conditions.

\subsubsection{Trueness}

The trueness of a method is considered as the measure of how the average value obtained by a large series of measurement using the method in specific conditions and the reference value are differing from one another. Measurements from suitable reference materials are performed to investigate the trueness of a method. Only one certified reference material with assigned SI-traceable values was commercially available i.e. the positive electrophoretic mobility standard reference material provided by the NIST, which allowed to investigate the positive charge of particles. There was one negative zeta potential reference material provided by Malvern and classified as a Transfer standard. This standard has been referenced to an 
accepted standard. In this case, the trueness may be not estimated in ideal conditions. The use of this standard was considered as the best alternative to investigate the negative charge of particles. Measurements were performed under intermediate precision to evaluate the trueness of the protocol. The data used for the evaluation of relative standard uncertainty of trueness are given in Appendix E. Uncertainties of trueness were 4.3 and $2.4 \%$ for the negative and positive standards respectively. The absolute bias was lower to its expanded uncertainty for both standards. There was no significant difference between the measured mean value and the certified value. The relative standard uncertainty of trueness for electrophoretic mobility measurement procedure for reference materials should be lower than $10 \%$ according to the standard ISO [5]. As no indication were provided for zeta potential, this threshold was considered as the limit value for the relative standard uncertainty of trueness of zeta potential values for the negative standard. For both standards, the relative standard uncertainty was less than the threshold defined by the standard ISO [5]. Thus, the trueness provided from the application of the proposed protocol is within acceptable limits.

\subsubsection{Measurement uncertainty}

An overview of the obtained relative standard uncertainty estimated from the repeatability, the intermediate precision and the trueness data is given in Fig. 4.

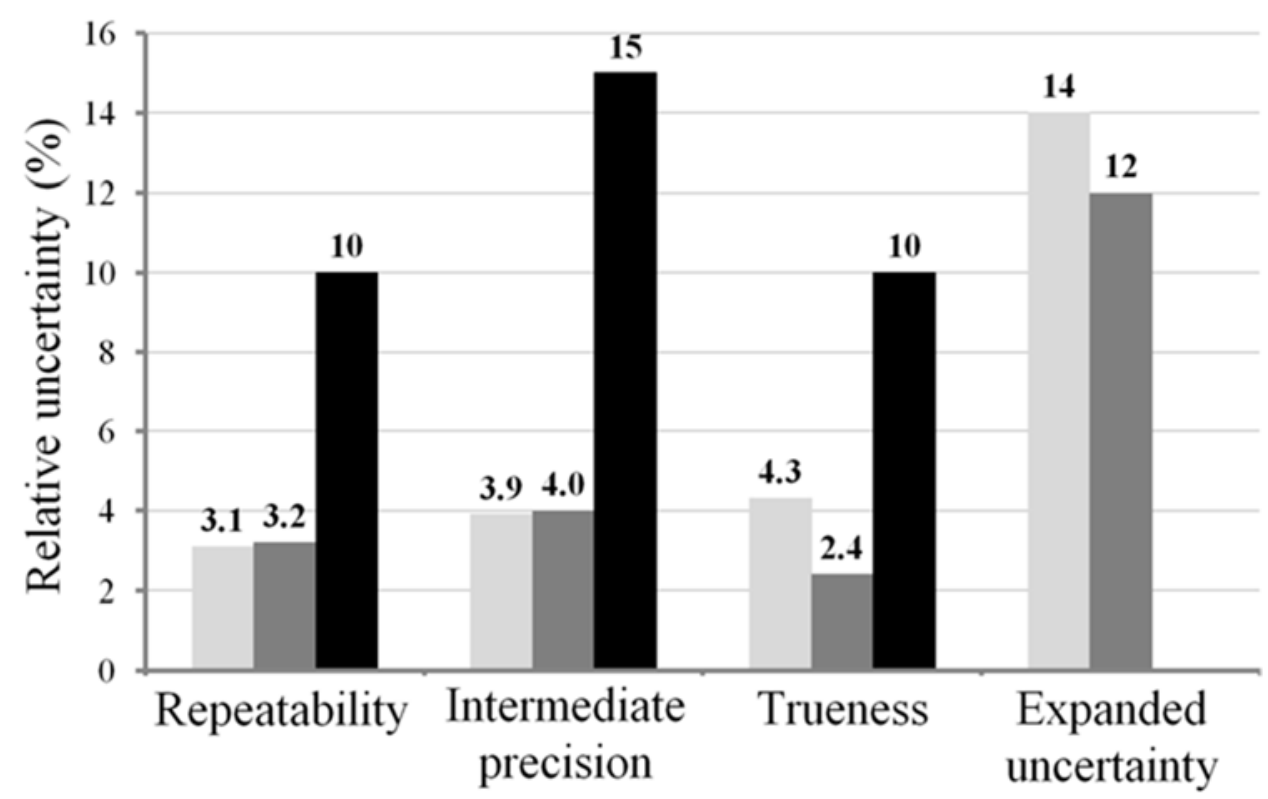

Fig. 4. Relative standard and expanded measurement uncertainties (\%). Light grey: negative standard, dark grey: positive standard, black: thresholds defined in the standard ISO [5].

The expanded uncertainties were lower than $15 \%$ for negative and positive standards for determination of zeta potential by ELS with Phase Analysis Light Scattering using the General Purpose analysis model. The relative standard uncertainties of repeatability, intermediate precision and trueness were well below thresholds defined by the standard ISO [5] showing the relevance and acceptable performance of the 
protocol proposed in this work. It is noteworthy that although this technique of analysis is perceived as straightforward; the achievement of the performance reached in this work was obtained at the expenses of lots of precautions including the selection of measurement cells by checking their optical quality, the carefully washing of cells with filtered solvents and storage in a dust-free environment, the filtration of all dispersants, the washing of flasks used for preparation of samples with filtered solvents, the carefully filling of the cells with the samples and the control of a series of factors such as the batch of cells, $T_{s}$, the type of cells and the analyst. While respecting all precautions, $T_{s}$ was found to be a critical factor that can be related to its effect on the viscosity of the dispersant. Results showed that samples have to be prepared at temperature closed to $T_{m}$ to avoid artifacts due to the temperature. The type of cells that implies use of different volume samples did not affect the results of the measurements after an equilibration time of 300 seconds as selected in the suggested protocol. The batch of cells was not a critical factor as there was no statistical difference between measurements made with different batches of cells of good quality (no scratches on optical faces, clean electrodes, tightly fixed electrodes). All analysts provided with equivalent results for zeta potential measurements taking into account all precautions.

To our knowledge, no validation of an operating protocol for zeta potential measurement by ELS using PALS was published so far. It is noteworthy that the standard ISO [4-6] and official guidances [3] mention other methods as EAS for the determination of zeta potential of nanomaterials. Although used to evaluate zeta potential of materials [41-45], no validation of zeta potential measurement protocol using EAS were reported in the literature. Other methods of electrophoresis as gel electrophoresis and capillary electrophoresis usually used for separation and purification of biomolecules can further provide zeta potential of nanomaterials [46] but no validation of protocol of measurements were reported in the literature so far.

\subsection{Example of application of the protocol to the determination of zeta potential of polymer nanoparticles}

ELS is used to determine the zeta potential of nanomaterials as described in official guidances [3]. Zeta potential of some nanomaterials used in nanomedicine as polymer nanoparticles was investigated to conclude this work. The entire approach developed in the protocol of zeta potential measurement proposed in this work was applied to perform measurements on these nanomaterials. This included (i) the control of the absence of absorption band in the visible region of spectra of the nanomaterials, (ii) the determination of optimal concentration of dispersions of nanomaterials to perform zeta potential measurements by ELS and (iii) the measurement of the zeta potential of the nanomaterials considering all precautions of manipulations, crucial factors highlighted by the validation and defined quality criteria for 
good zeta potential measurements. It is noteworthy that all these measurements were carried out under operational qualification of the instrument.

\subsubsection{Spectral characteristics of nanoparticle dispersions}

None of the dispersions selected as examples of polymer nanoparticles to determine zeta potential with the protocol proposed in this work presented an absorption band at the wavelength of $633 \mathrm{~nm}$ at $25^{\circ} \mathrm{C}$ (Appendix F). This indicated that zeta potential of these nanoparticles can be evaluated by ELS using an instrument equipped with a laser source with a wavelength ranging from 400 to $800 \mathrm{~nm}$.

\subsubsection{Preconditioning measurement cells with sample}

As for measurements of the positive standard, polymer nanoparticles expected to be positive may adsorb on the measurement cell material implying that the cells need to be preconditioned with the sample prior performing analysis. In the series of nanoparticles taken as examples, the PIBCA nanoparticles decorated with chitosan were expected to bear positive charges due to the aminogroups of the glucosamine residues found in the chitosan chain. Thus, different cells were preconditioned with the nanoparticles for 0,1 , and $10 \mathrm{~min}$. The average zeta potential obtained are given in Table 12.

Table 12. Average zeta potential obtained for different conditioning time with PIBCA nanoparticles decorated with chitosan.

\begin{tabular}{cc}
\hline Conditioning time $(\mathrm{min})$ & Average zeta potential $(\mathrm{mV})$ \\
\hline 0 & 32 \\
1 & 31 \\
10 & 30 \\
\hline \multirow{2}{*}{ Average } & $31( \pm 1)$ \\
& $\mathrm{CV}=3.3 \% *$ \\
\hline
\end{tabular}

*Coefficient of variation.

The coefficient of variation related to all conditioning times was less than $5 \%$ showing no significant influence on the preconditioning time of measurement cells with these nanoparticles. AFM of the surface cells having been in contact with the sample showed few particles that adsorbed (Fig. 5 (g)). The PIBCA nanoparticles decorated with chitosan interacted only slightly with the measurement cell surface explaining that there was no influenced of a preconditioning time of the cell. It can be concluded that zeta potential measurements on these nanoparticles can be made without the need of preconditioning of the measurement cells. 


\subsubsection{Optimization of the concentration of the nanoparticle dispersion to perform zeta} potential measurements by ELS

Concentrations of the dispersions were optimized in order to obtain sufficient signal transmitted to the detector in the one hand and to avoid multiple scattering phenomena and/or particle-particle interactions in the other hand. The minimum and maximum concentrations of the samples depended on nanoparticle optical properties including their refractive index, particle size and polydispersity index. While a minimum count rate of $20 \mathrm{kcps}$ of the scattered light is needed to perform measurements, the intensity of the scattered light received $y$ the detector is compensated by an attenuator that modulates the received light as a function of the concentration of the sample [38].

To find the optimal concentration of nanoparticles to introduce in the measurement cells, zeta potential was measured on a series of dilutions of the sample. The attenuation selected by the instrument was then plotted against the concentration of the sample as well as the corresponding value of zeta potential. Results obtained for nanoparticles coated with dextran, with dextran sulfate and with chitosan are presented in Fig. 5 (a), Fig. 5 (b) and Fig. 5 (c) respectively. A high value of the attenuator means a low attenuation of the laser beam. For all particles, similar trends were observed. At low concentrations, low attenuation was applied and values of zeta potential varied. As the concentration increased, much attenuation was applied to reach a plateau value while the value of the zeta potential tended to also stabilize. At the highest concentrations in particles, the attenuation was reduced and a variation of zeta potential was observed. At a high concentration of nanoparticles, multiple scattering may interfere decreasing the intensity of the scattered light. Optimal concentrations of dispersions were selected at the centre of the plateau values of the attenuator and zeta potential. It is noteworthy that defined quality criteria given by the instrument and evaluated by examination of the phase plot and the frequency plot were not met at the lower and higher range of concentrations as indicated on Fig. 5. In contrast, the concentration selected to perform zeta potential measurements was comprised in the range of concentrations for which all quality criteria were met. 

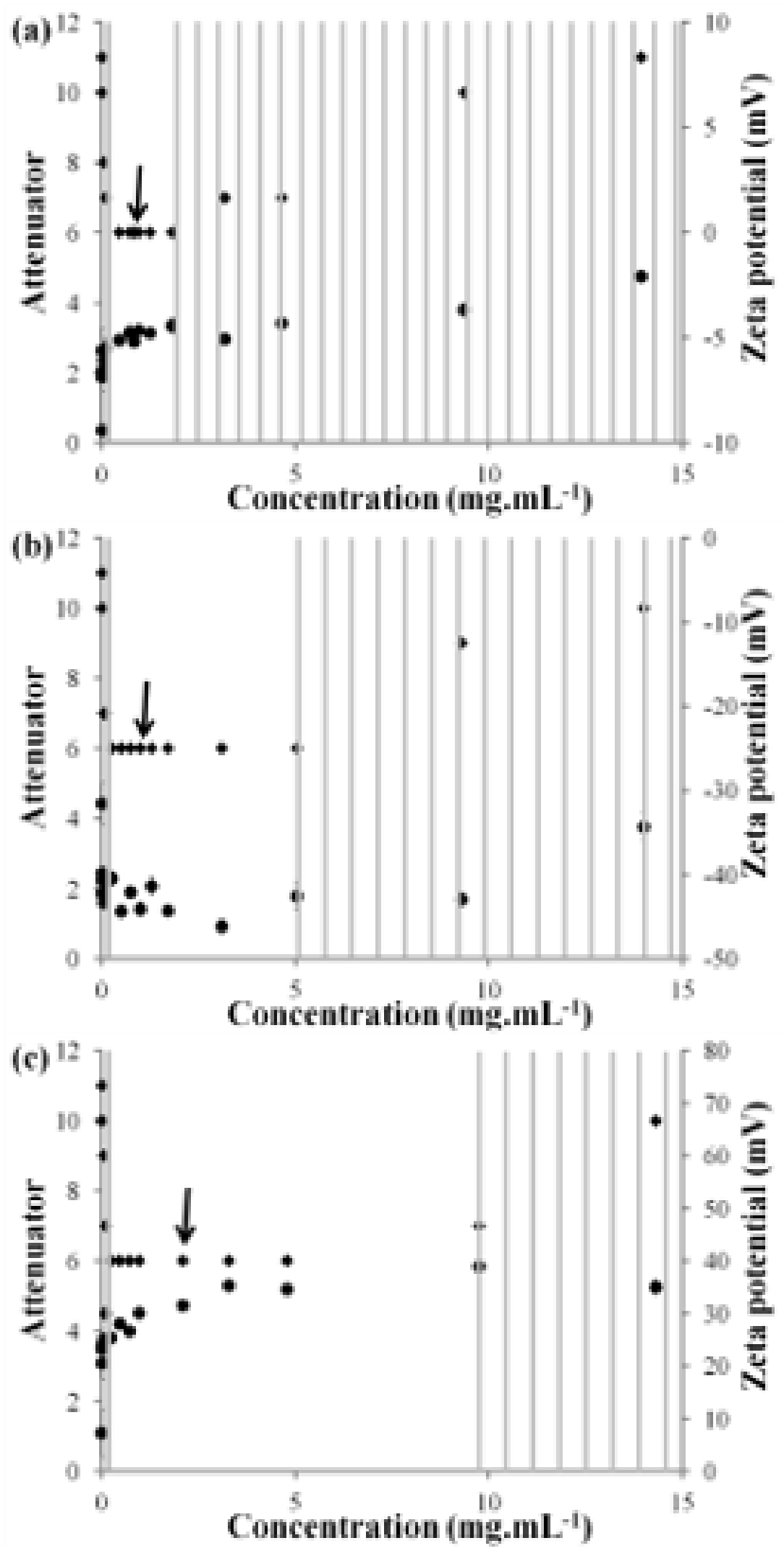

Fig. 5. Optimization of the concentration of dispersions of polymer nanoparticles to perform zeta potential measurements by ELS at $25^{\circ} \mathrm{C}$. (a) PIBCA nanoparticles decorated with dextran. (b) PIBCA nanoparticles decorated with dextran sulfate. (c) PIBCA nanoparticles decorated with chitosan. Diamonds and circles indicated attenuator and zeta potential respectively. On graphs, hashed parts indicated ranges of concentration for which defined quality criteria were not satisfied. Arrows point out selected dilutions to perform zeta potential measurements. 


\subsubsection{Measurements of zeta potential of polymer nanoparticles}

Results of zeta potential measurements obtained for polymer nanoparticles coated with polysaccharide are given in Table 13. All defined quality criteria for good zeta potential measurements were satisfied. Operational qualification of the instrument was carried out to prove that the instrument was operating in agreement with its specification with the standards used for the validation before and after zeta potential measurements of nanomaterials tested and using the protocol that was validated in this work. Results of qualification are presented in Appendix L.

Table 13. Results from measurements of zeta potential performed on PIBCA nanoparticles decorated with different polysaccharide.

\begin{tabular}{ccc}
\hline $\begin{array}{c}\text { Polysaccharide stranded } \\
\text { on the nanoparticle surface }\end{array}$ & zeta potential $(\mathrm{mV})$ & $\begin{array}{c}\text { Z-average } \\
\text { diameter }(\mathrm{nm})^{*}\end{array}$ \\
\hline Dextran & $-5.0 \pm 14 \%^{* *}$ & $241 \pm 10$ \\
Dextran sulfate & $-42 \pm 14 \%^{* *}$ & $253 \pm 10$ \\
Chitosan & $31 \pm 12 \%^{* * *}$ & $394 \pm 16$ \\
\hline
\end{tabular}

* Determined by DLS.

**The estimated expanded uncertainty determined from zeta potential measurement of negative standard was applied to zeta potential measurements of tested nanomaterials bearing negative charges.

***The estimated uncertainty obtained for positive standard was applied to the measurement of zeta potential of tested nanomaterials bearing positive charges.

The protocol that was validated in this work was found suitable to be applied to zeta potential measurements of polymer nanoparticles. Additional zeta potential measurements on other types of nanomaterials should be performed to evaluate the scope of this analysis model based on combination of FFR and SFR.

\section{Conclusion}

This paper presents a methodology to perform a validation of a measurement protocol including the approach to achieve statistical analysis of the results obtained from measurements. It proposes the standardization and the validation of a protocol for the determination of zeta potential of nanomaterials by ELS with PALS using the General Purpose analysis model of a Zetasizer Nano ZS (Malvern) equipped with a laser source of wavelength of $633 \mathrm{~nm}$ with scattered angle fixed at $13^{\circ}$. Using two standards, the proposed protocol was proven to be robust and suitable for determination of negative charged nanoparticles and positive charged nanoparticles having considered factors including batch of cells, temperature of the sample, type of cells and analyst. Relative standard uncertainties of repeatability, intermediate precision and trueness were below the threshold defined by the standard ISO [5]. The proposed protocol was found 
to be precise under repeatability conditions and defined intermediate precision conditions. Its trueness was within acceptable limits. At least, a methodology for the application of this protocol to the measurement of the zeta potential of unknown non-conducting polymer nanoparticles dispersed in aqueous medium with low concentration of electrolyte within the range of the application of Smoluchowski's model was described. The protocol was found suitable to measure the zeta potential of polymer nanoparticles of different compositions. Further analysis will be needed to extend the scope of this protocol to the determination of nanomaterials of a wider range of composition.

\section{Acknowledgement}

This work was supported by Bpl France (Project NICE). The authors thank Michel Terray, Céline Cottier and Aline Banzet from Malvern and Dr Thomas Linsinger from European Commission - Joint Research Centre Institute for Reference Materials and Measurements (IRMM) for fruitful discussions. The authors want to thank Dr Gillian Barratt and Dr François-Xavier Legrand from CNRS UMR 8612 Institut Galien Paris-Sud for productive discussions.

\section{References}

[1] Report of the Joint Regulator -Industry Ad Hoc Working Group: Currently Available Methods for Characterization of Nanomaterials, 17 June 2011.

http://ec.europa.eu/consumers/sectors/cosmetics/files/pdf/iccr5_char_nano_en.pdf (consulted on May 2015).

[2] Organization for Economic Co-operation and Development (OCDE), Guidance manual for the testing of manufactured nanomaterials: OECD's sponsorship programme; First revision ENV/JM/MONO(2009)20/REV, 2 June 2010.

http://search.oecd.org/officialdocuments/displaydocumentpdf/?cote=env/jm/mono\%282009\%2920/rev\& doclanguage $=e n$ (consulted on May 2015).

[3] FDA advisory committee for pharmaceutical science and clinical pharmacology meeting Topic 2 Nanotechnology - Update on FDA Activities, 9 August 2012.

http://www.fda.gov/downloads/AdvisoryCommittees/CommitteesMeetingMaterials/Drugs/AdvisoryComm itteeforPharmaceuticalScienceandClinicalPharmacology/UCM314585.pdf (consulted on May 2015).

[4] ISO 13099-3:2012(E): Colloidal systems - Methods for zeta-potential determination - Part 1: Electroacoustic and electrokinetic phenomena.

[5] ISO 13099-2:2012(E): Colloidal systems - Methods for zeta-potential determination - Part 2: Optical methods.

[6] ISO 13099-3:2012(E): Colloidal systems - Methods for zeta-potential determination - Part 3: Acoustic methods.

[7] P.-C. Lin, S. Lin, P.C. Wang, R. Sridhar, Techniques for physicochemical characterization of nanomaterials, Biotechnol. Adv. 32(4) (2014) 711-726.

[8] NCL Method PCC-2, Measuring Zeta Potential of Nanoparticles, April 2008, revised November 2009.

http://ncl.cancer.gov/NCL_Method_PCC-2.pdf (consulted on May 2015).

[9] ISO 5725-1:1994: Accuracy (trueness and precision) of measurement methods and results - Part 1: General principles and definitions. 
[10] ICH Harmonized Tripartite Guideline, Validation of analytical procedures: Text and Methodology Q2(R1), Current Step 4 version, Parent Guideline dated 27 October 1994, (Complementary Guideline on Methodology dated 6 November 1996 incorporated in November 2005).

http://www.ich.org/fileadmin/Public_Web_Site/ICH_Products/Guidelines/Quality/Q2_R1/Step4/Q2_R1_ Guideline.pdf (consulted on May 2015).

[11] Guide to the expression of uncertainty in measurement, JCGM 100:2008 GUM 1995 with minor corrections.

http://www.bipm.org/utils/common/documents/jcgm/JCGM_100_2008_E.pdf (consulted on May 2015).

[12] ISO Guide 35:2006: Reference materials - General and statistical principles for certification.

[13] I. Bertholon, C. Vauthier, D. Labarre, Complement Activation by Core-Shell Poly(isobutylcyanoacrylate)Polysaccharide Nanoparticles: Influences of Surface Morphology, Length, and Type of Polysaccharide, Pharmaceut. Res. 23(6) (2006) 1313-1323.

[14] C. Chauvierre, D. Labarre, P. Couvreur, C. Vauthier, Novel Polysaccharide-Decorated Poly(Isobutyl Cyanoacrylate) Nanoparticles, Pharmaceut. Res., 20(11) (2003) 1786-1793.

[15] C. Zandanel, C. Vauthier, Poly(isobutylcyanoacrylate) nanoparticles decorated with chitosan: Effect of conformation of chitosan chains at the surface on complement activation properties, J. Colloid Sci. Biotechnology 1 (2012) 68-81.

[16] I.S. Bouhaik, P. Leroy, P.Ollivier, M. Azaroual, L. Mercury, Influence of surface conductivity on the apparent zeta potential of $\mathrm{TiO}_{2}$ nanoparticles: Application to the modeling of their aggregation kinetics, J. Colloid Interf. Sci. 406 (2013) 75-85.

[17] P. Leroy, N. Devau, A. Revil, M Bizi, Influence of surface conductivity on the apparent zeta potential of amorphous silica nanoparticles, J. Colloid Interf. Sci. 410 (2013) 81-93.

[18] Z. Adamczyk, M. Zaucha, M. Zembala, Zeta Potential of Mica Covered by Colloid Particles: A Streaming Potential Study, Langmuir 26(12) (2010) 9368-9377.

[19] Malvern, Zetasizer Nano series Technical Note, Zeta Potential An Introduction in 30 Minutes, 2014 (available on Malvern's site, required registration to access to this note, consulted on May 2015).

[20] Y. Vander Heyden, K. De Braekeleer, Y. Zhu, E. Roets, J. Hoogmartens, J. De Beer, D.L. Massart, Nested designs in ruggedness testing, J. Pharmaceut. and Biomed. 20 (1999) 875-887.

[21] X. Wang, M.C. Chambers, L.J. Vega-Montoto, D.M. Bunk, S.E. Stein, D.L. Tabb, QC Metrics from CPTAC Raw LC-MS/MS Data Interpreted through Multivariate Statistics, Anal. Chem. 86 (2014) 2497-2509.

[22] M. Careri, L. Elviri, A. Mangia, Development and Validation of a Method Using On-Line Solid-Phase Extraction and Liquid Chromatography with Ultraviolet Detection for the Determination of Bisphenol A, Octylphenol, and Nonylphenol in Groundwater, J. AOAC Int. 84(5) (2001) 1383-1392.

[23] O.H. J. Szolar, S. Stranner, I. Zinoecker, G.C. Mudde, G. Himmler, G. Waxenecker, A. Nechansky, Qualification and application of a surface plasmon resonance-based assay for monitoring potential HAHA responses induced after passive administration of a humanized anti Lewis-Y antibody, J. Pharmaceut. Biomed. 41 (2006) 1347-1353.

[24] J. Wang, D. Leung, W. Chow, Applications of LC/ESI-MS/MS and UHPLC QqTOF MS for the Determination of 148 Pesticides in Berries, J. Agric. Food Chem. 58 (2010) 5904-5925.

[25] A. Oliva, J.B. Fariña, M. Llabrés, Measurement of uncertainty in peptide molecular weight determination using size-exclusion chromatography with multi-angle laser light-scattering detection and matrix-assisted laser desorption/ionization time-of-flight mass spectrometry, Anal. Chim. Acta 512 (2004) 103-110.

[26] S. Kuttatharmmakul, D.L. Massart, J. Smeyers-Verbeke, Comparison of alternative measurement methods, Anal. Chim. Acta 391 (1999) 203-225.

[27] J. Wang, W. Chow, D. Leung, Applications of LC/ESI-MS/MS and UHPLC QqTOF MS for the determination of 148 pesticides in fruits and vegetables, Anal. Bioanal. Chem. 39(4) (2010) 1513-1538.

[28] J. Wang, D. Leung, F. Butterworth, Determination of Five Macrolide Antibiotic Residues in Eggs Using Liquid Chromatography/Electrospray lonization Tandem Mass Spectrometry, J. Agric. Food Chem. 53 (2005) 1857-1865.

[29] J. Wang, D. Wotherspoon, Determination of Pesticides in Apples by Liquid Chromatography with Electrospray lonization Tandem Mass Spectrometry and Estimation of Measurement Uncertainty, J. AOAC Int. 90(2) (2007) 550-567. 
[30] J. Wang, W. Cheung, W. Chow, Ultra-High Performance Liquid Chromatography/Electrospray Ionization-Tandem Mass Spectrometry Determination of 151 Pesticides in Soybeans and Pulses, J. AOAC Int. 96(5) (2013) 1114-1133.

[31] J. Wang, W. Chow, D. Leung, Applications of LC/ESI-MS/MS and UHPLC/Qq-TOF-MS for the Determination of 141 Pesticides in Tea, J. AOAC Int. 94(6) (2011) 1685-1714.

[32] ISO 5725-3:1994: Accuracy (trueness and precision) of measurements methods and results - Part 3: Intermediate measures of the precision of a standard measurement method.

[33] F. Varenne, J. Botton, C. Merlet, M. Beck-Broichsitter, F. -X. Legrand, C. Vauthier, Standardization and validation of a protocol of size measurements by dynamic light scattering for monodispersed stable nanomaterial characterization, submitted for publication.

[34] D.C. Howell, Méthodes statistiques en sciences humaine (Translation of the original Work: Statistical Methods for Psychology, $6^{\text {th }}$ ed., 2006 Cengage Learning, by M. Rogier, V. Yzerbyt and Y. Bestgen), Second $2^{\text {nd }}$ ed., $4^{\text {th }}$ Impression, De Boeck, Louvain-La-Neuve, 2014.

[35] L. Chanquoy, Statistiques appliquées à la psychologie et aux sciences humaines et sociales, Hachette, Paris, 2005.

[36] Minitab 16, Statistical software Minitab Inc, State College, Pennsylvania.

[37] T. Linsinger, ERM Application Note 1: Comparison of a measurement result with the certified value (2005).

[38] Malvern, Technical Note, Concentration Limits for Zeta Potential Measurements in the Zetasizer Nano.

[39] B.J. Tan, K.J. Klabunde, P.M.A. Sherwood, X-ray photoelectron spectroscopy studies of solvated metal atom dispersed catalysts. Monometallic iron and bimetallic iron-cobalt particles on alumina, Chem. Mater. 2 (1990) 186-191.

[40] Malvern, Zetasizer Nano Series User Manual, Issue 1.1, April 2013

[41] R.W. O'Brien, D.W. Cannon, W.N. Rowlands, Electroacoustic Determination of Particle Size and Zeta Potential, J. Colloid Interf. Sci. 173 (1995) 406-418.

[42] V. Adibnia, R.J. Hill, Electroacoustic Spectroscopy of Nanoparticle-Doped Hydrogels, Macromolecules 47(22) (2014) 8064-8071.

[43] A.S. Dukhin, S. Parlia, Measuring zeta potential of protein nano-particles using electroacoustics, Colloid. Surface. B 121 (2014) 257-263.

[44] J. Godnjavec, J. Zabret, B. Znoj, S. Skale, N. Veronovski, P. Venturini, Investigation of surface modification of rutile $\mathrm{TiO}_{2}$ nanoparticles with $\mathrm{SiO}_{2} / \mathrm{Al}_{2} \mathrm{O}_{3}$ on the properties of polyacrylic composite coating, Prog. Org. Coat. 77 (2014) 47-52.

[45] T. Rheinländera, T. Priester, M. Thommes, Novel physicochemical characterization of magnetic fluids, J. Magn. Magn. Mater. 256 (2003) 252-261.

[46] K.E. Sapsford, K.M. Tyner, B.J. Dair, J.R. Deschamps, I.L. Medintz, Analyzing nanomaterial bioconjugates: a review of current and emerging purification and characterization techniques, Anal. Chem. 83(12) (2011) 4453-4488. 


\title{
Standardization and validation of a protocol of zeta potential evaluation by electrophoretic light scattering for nanomaterial characterization
}

\author{
Fanny Varenne ${ }^{a, b}$, Jérémie Botton ${ }^{c, d}$, Claire Merlet ${ }^{a, b}$, Jean-Jacques Vachon ${ }^{a, b}$, \\ Sandrine Geiger ${ }^{\mathrm{a}, \mathrm{b}, \mathrm{e}}$, Ingrid C. Infante ${ }^{\mathrm{e}}$, Mohamed Chehimi ${ }^{f}$, Christine Vauthier ${ }^{\mathrm{a}, \mathrm{b}^{*}}$. \\ a Univ Paris-Sud, Institut Galien Paris-Sud, Faculty of Pharmacy, Châtenay-Malabry, France \\ ${ }^{\mathrm{b}}$ CNRS UMR 8612, Institut Galien Paris-Sud, Châtenay-Malabry, France \\ ' Univ Paris-Sud, Faculty of Pharmacy, Châtenay-Malabry, France \\ d INSERM UMR 1153, Epidemiology and Biostatistics Sorbonne Paris Cité Center (CRESS), Team " Early \\ Origin of the Child's Health and Development " (ORCHAD), University Paris Descartes, Paris, France \\ e Laboratory "Structures, Propriétés et Modélisation des Solides», UMR 8580, CNRS \& Centrale Supélec, \\ University Paris-Saclay, Châtenay-Malabry, France \\ ${ }^{f}$ Paris Est University, ICMPE (UMR 7182), SPC, UPEC, Thiais, France
}

\section{Appendix - Supplementary data}




\section{Appendix A: Reference of standards used}

Table A.1. References of the standards used for the validation.

\begin{tabular}{ccc}
\hline Characteristic & Negative standard & Positive standard \\
\hline Supplier & Malvern & National Institute of Standards \\
Reference & DTS 1235 & $\begin{array}{c}\text { and Technology (NIST) } \\
\text { Standard Reference Material 1980 } \\
\text { Batch }\end{array}$ \\
Certified date & NS & See certified expiration date \\
Expiration date* & 28 February 2015 & 15 October 2012 \\
Type of & Reference material & Certified reference material \\
standard & & \\
\hline
\end{tabular}

NS: Not specified.

*All experiments were carried out before expiration date. 


\section{Appendix B: Quality criteria for good measurements}

The selection of the cells and the preparation of the samples were essential to obtain reliable results together with considerations regarding the preparation of the samples for measurements including the drastically selection of the measurement cells, different controls were achieved during measurements and on the measurements data to achieve quality of the measures as it was explained below.

\section{B.1. Selection of measurement cells and preparation of samples for measurements}

Cells with high optical quality are needed to perform zeta potential measurements. Disposable cells in polycarbonate with two gold-plated electrodes were provided by the supplier of the instrument and were used to avoid cross-contamination. Cells were handled with powder- free containing latex or nitrile gloves to avoid deposition of dust on the cells. Cells and caps were rinsed thoroughly before use with filtered ultrapure water followed by filtered ethanol and finally filtered ultrapure water using disposable syringe and using a $0.22 \mu \mathrm{m}$ filter membrane. $10 \mathrm{~mL}$ of filtered ultrapure water were flushed by each port of the cells and $5 \mathrm{~mL}$ of filtered ethanol were flushed by each port of the cells to thoroughly rinse each electrode. Before and after rinsing, cells were controlled for surface scratches or apparent impurity in the polycarbonate that might interfere with optical measurements. It was checked that electrodes both inside and outside of the cell were clean and tightly fixed on the cell. Any cell that did not meet these criteria was discard. After final inspection and cleaning, the cells were stored capped and in a dust-free environment. Syringes were used to fill measurement cells with the sample as recommended by the supplier of the equipment and described in Fig. B.1. Cells were used only once.

Dispersant used as to dilute dispersions was filtered prior to sample preparation using a $0.22 \mu \mathrm{m}$ filter. All flasks used for dilution including caps were rinsed three times with filtered ultrapure water and stored in a dust-free environment after preparation.

Spectral properties of each sample were checked. No absorption band were observed in the visible region. Absorption spectra were recorded using accurate UV-Vis spectrometer. 


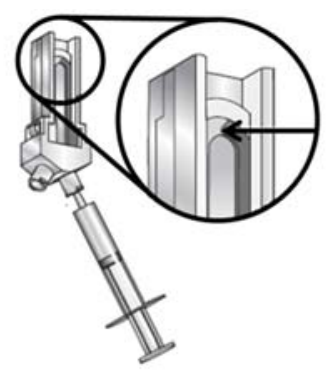

Step 1: Half of the cell was filled out while the cell was upside down. The sample was injected with a syringe without introducing

Step 2: The cell was turned in the right position and continued to fill to the maximum level without introducing bubbles. Note that the maximum level of filling was different depending on the factor type of cells. For cells DTS 1070, the liquid level reached the maximum height marked by the line " FILL MAX". For cells DTS 1060, the cell was filled completely. The cells were inspected for bubbles and the electrodes were checked

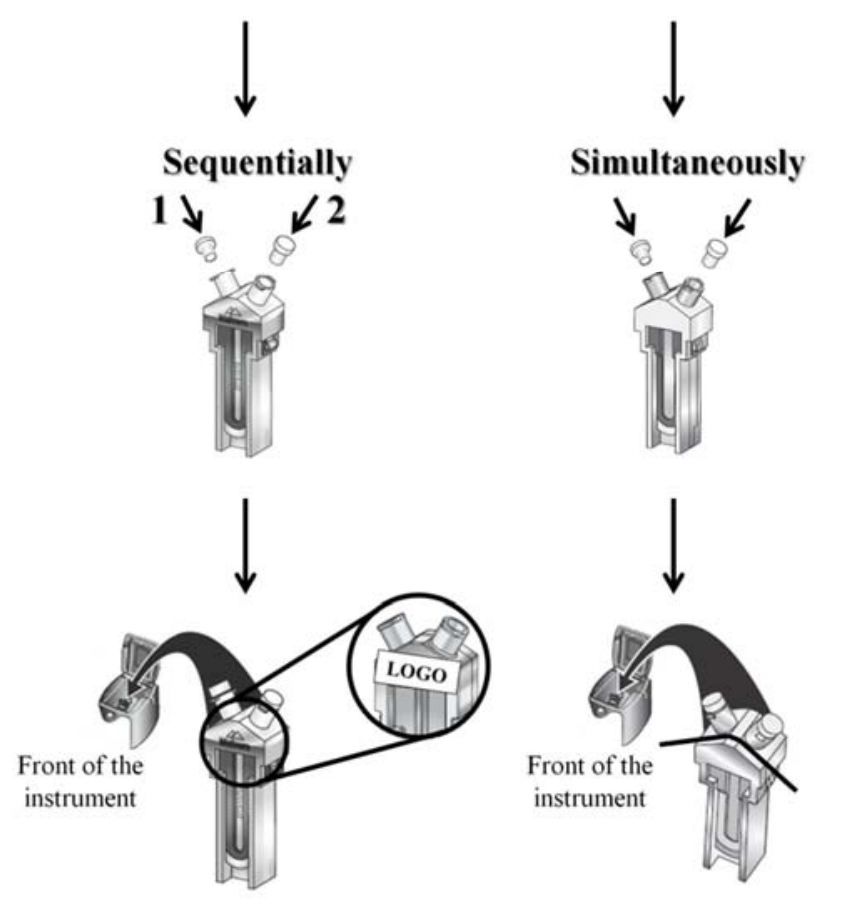

Step 3: The filled cells were capped. This operation depended on the factor type of cells. For cells DTS 1070, one port was tightly capped and the second cap was then placed on the second port with precaution to avoid causing cell pressure. For cells DTS 1060 , both caps were simultaneously placed on ports to obtain the same liquid level at each port of the cell. The cells were further inspected for bubbles and the outside was

Step 4: The cell was inserted into the sample holder of the instrument in the right position. For cells DTS 1070, the logo was oriented towards the front of the instrument. For cells DTS 1060, the cell weld line sharing the cell into two parts with different widths was used to orient the cells. The narrower part defining this line was oriented towards the front of the

Fig. B.1. Method for filling measurement cells with samples (steps 1 to 3) and positioning the cells into the instrument (step 4). Cell adapted from [1] with permission. 


\section{B.2. Controls achieved during analysis}

\section{Phase plot}

The phase plot must be checked during each run. It should be well defined without noise. The Fig. B.2 shows a good quality phase plot obtained for the analysis of negative standard. Results considered were all obtained from analysis that showed a phase plot as illustrated in Fig. B.2.

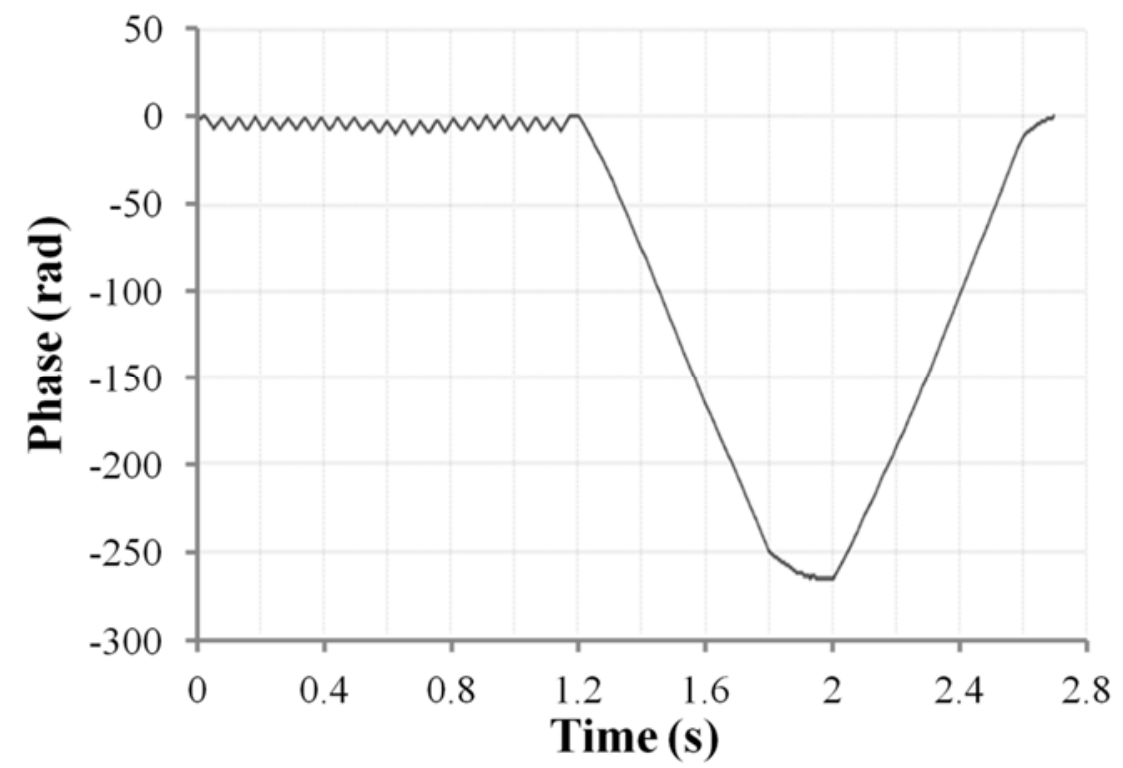

Fig. B.2. Phase plot obtained from screen print taken up during the measurement of negative standard (Malvern, DTS1235, Batch: 091408, - $42 \pm 4.2 \mathrm{mV}$, Expiration date: February 2015, Analysis date: May 2014), measurement value: - $41.1 \pm 0.7 \mathrm{mV}$ using General Purpose analysis model.

\section{Count Rate curve}

The count rate curve corresponds to the number of photons detected by the photomultiplier per second. The count rate must be stable over time. Unstable curves can be providing by dust in the sample or the presence or aggregates. For example, two count rate curves are shown in Fig. B.3, one resulting from the analysis of negative standard (Fig. B.3 (a)) and the other from the analysis of dispersion $113 \pm 10 \mathrm{~nm}$ diluted with $\mathrm{NaCl} 15.4 \mathrm{mM}$ (Fig. B.3 (b)). In the latter case, peaks with high signals appeared randomly due to the presence of bubbles adjacent to electrodes. Only measures presenting a stable count rate curve were considered for fulfilling the good measurement quality criteria. 

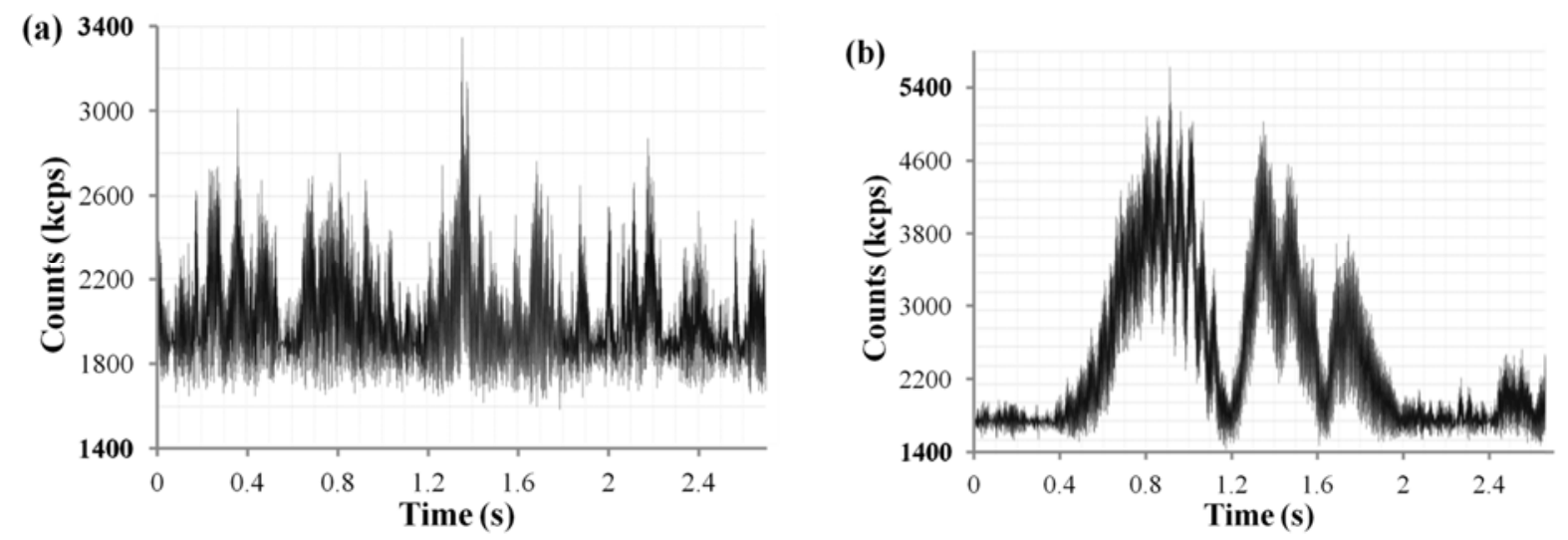

Fig. B.3. (a) Count rate plot obtained from screen print taken up during the measurement of negative standard (Malvern, DTS1235, Batch: 091408, - $42 \pm 4.2 \mathrm{mV}$, Expiration date: February 2015, Analysis date: May 2014), measurement value: - $41.1 \pm 0.7 \mathrm{mV}$ using General Purpose analysis model. (b) Count rate plot obtained from screen print taken up during the measurement of dispersion $113 \pm 10 \mathrm{~nm}$ (Polysciences Inc, 00876, Batch: 610905) diluted with $\mathrm{NaCl} 15.4 \mathrm{mM}$ using General Purpose analysis model. Presence of bubbles on the electrodes.

\section{B.3. Controls achieved on measurement data}

\section{Phase plot}

The final phase plot given for one measurement corresponds to the phase difference between the measured frequency and the reference frequency as a function of time. Two phase plots of good quality using the General-Purpose analysis model are shown in Fig. B.4 (a) and (b) for the negative and positive standards respectively. The first part of the phase plot presents well defined alternative slopes of the phase difference with time and smooth (without noise) which corresponds to the application of Fast Field Reversal for the determination of the mean value zeta potential. The second part is as " positive (Fig. B.4 (a)) or negative (Fig. B.4 (b)) peak » and corresponds to the application of Slow Field Reversal for the determination of the distribution of the zeta potential. The slopes of the phase difference with time and the « negative or positive peak » should be well defined and smooth (without noise). 

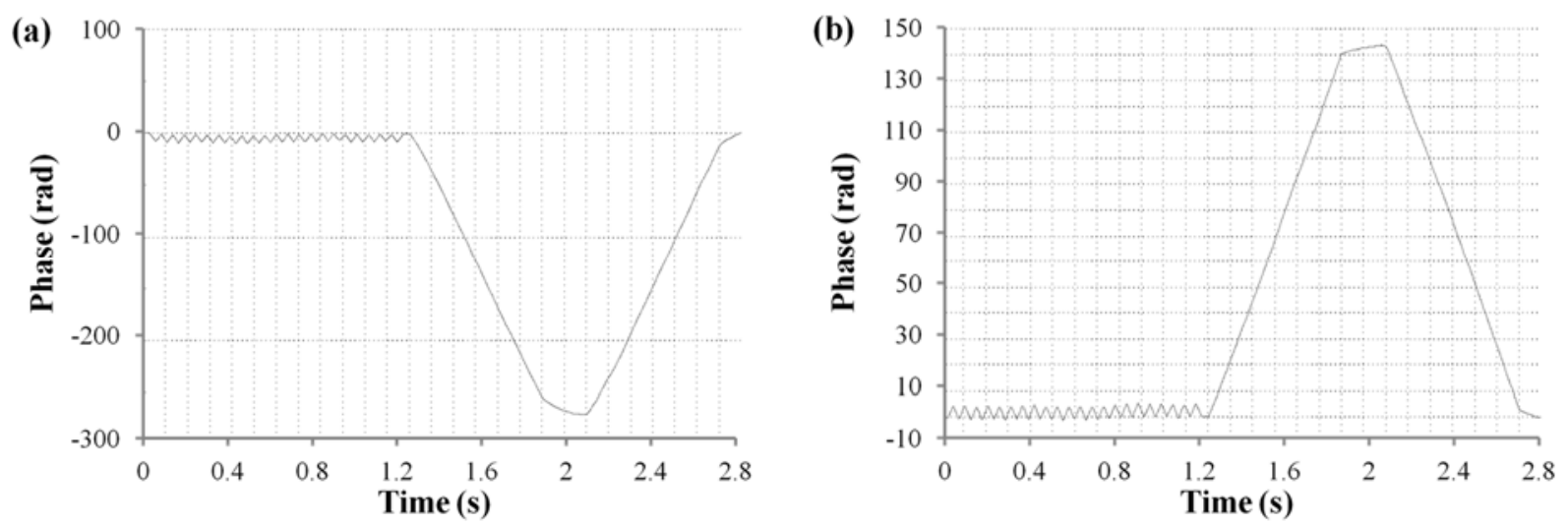

Fig. B.4. (a) Phase plot obtained for the measurement of negative standard (Malvern, DTS1235, Batch: 091408, - $42 \pm 4.2 \mathrm{mV}$, Expiration date: February 2015, Analysis date: May 2014), measurement value: - $41.1 \pm 0.7 \mathrm{mV}$ using General Purpose analysis model. (b) Phase plot obtained for the measurement of positive standard (NIST, SRM1980, $2.53 \pm 0.12 \mu \mathrm{m} . \mathrm{cm} . \mathrm{V}^{-1} . \mathrm{s}^{-1}$, Expiration date: September 2016, Analysis date: October 2015), measurement value: $2.50 \pm 0.08$ $\mu \mathrm{m} . \mathrm{cm} . V^{-1} . \mathrm{s}^{-1}$ using General Purpose analysis model.

For example, three poor quality phase plots are shown in Fig. B.5 using the General-Purpose analysis model, the one resulting from the analysis of aggregated particles (Fig. B.5 (a)), the second from the analysis of sedimenting particles (Fig. B.5 (b)) and the last from of the analysis of a dispersion $113 \pm 10 \mathrm{~nm}$ diluted with $\mathrm{NaCl} 15.4 \mathrm{mM}$ while bubbles were trapped on the electrodes (Fig. B.5 (c)).

Other factors may explain the poor quality of the plots including an inappropriate concentration of the sample or a high conductivity of the dispersion.

In ELS measurements, the minimum and the maximum concentrations dependent from various factors such as the optical properties, size and polydispersity of the particles. Dispersions for zeta potential measurements need to be quite transparent to let the incident laser light penetrate the dispersion for a detection of the scattered light at a certain angle from the transmitted and incident light. If sample concentration is too high, the intensity of the incident light is attenuated by particles hence the amount of detected scattered light is reduced. If the sample concentration is too low, insufficient signal may induce a poor signal to noise ratio. The concentration of dispersion have to be optimized as described in the technical note [2]. 


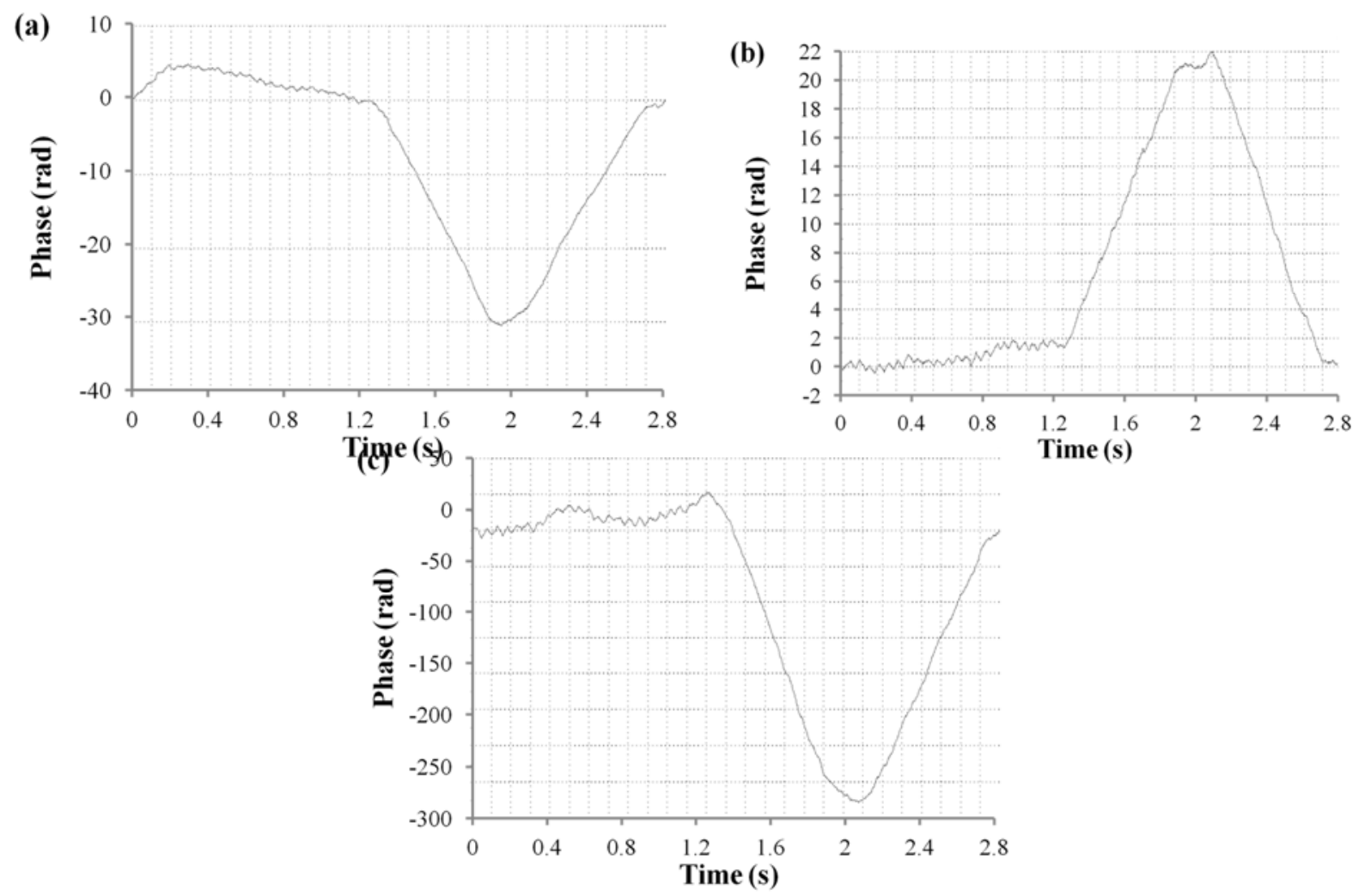

Fig. B.5. Examples of poor-quality phase plot in General-Purpose analysis model. (a) Aggregate particles bearing negative charges. (b) Sedimenting particles bearing positive charges. (c) Measurement of dispersion $113 \pm 10 \mathrm{~nm}$ bearing negative charges (Polysciences Inc, 00876, Batch: 610905) diluted with $\mathrm{NaCl} 15.4 \mathrm{mM}$. Presence of bubbles on the electrodes.

In case conductivity of the dispersion is too high, damages may occur within the dispersion and on the electrodes of the measurement cells. This effect can be observed when performing measurement with the General-Purpose analysis model due to the Joule's effect created by the application of the Slow Field Reversal (SFR). So, the supplier of the instrument recommends to use the Monomodal analysis model for the analysis of dispersion having conductivities higher than $5 \mathrm{mS} . \mathrm{cm}^{-1}$. It is noteworthy that no zeta potential distribution is given, and only mean zeta potential is determined in this mode.

Only samples showing a phase plot as illustrated in Fig. B.4 were considered.

\section{$\underline{\text { Frequency plot }}$}

The frequency plot is used to determine electrophoretic mobility distribution and consequently zeta potential distribution. The frequency plot is obtained from the SFR part of the measurement by means of Fourier transform analysis. A frequency plot obtained from a good measurement is presented in Fig. B.6 (a). A noisy and poor-quality frequency plot due to air bubbles is shown in 
Fig. B.6 (b). The baseline of the latter was not smooth. Results considered were all obtained from analysis that showed a frequency plot as shown in Fig. B.6 (a).
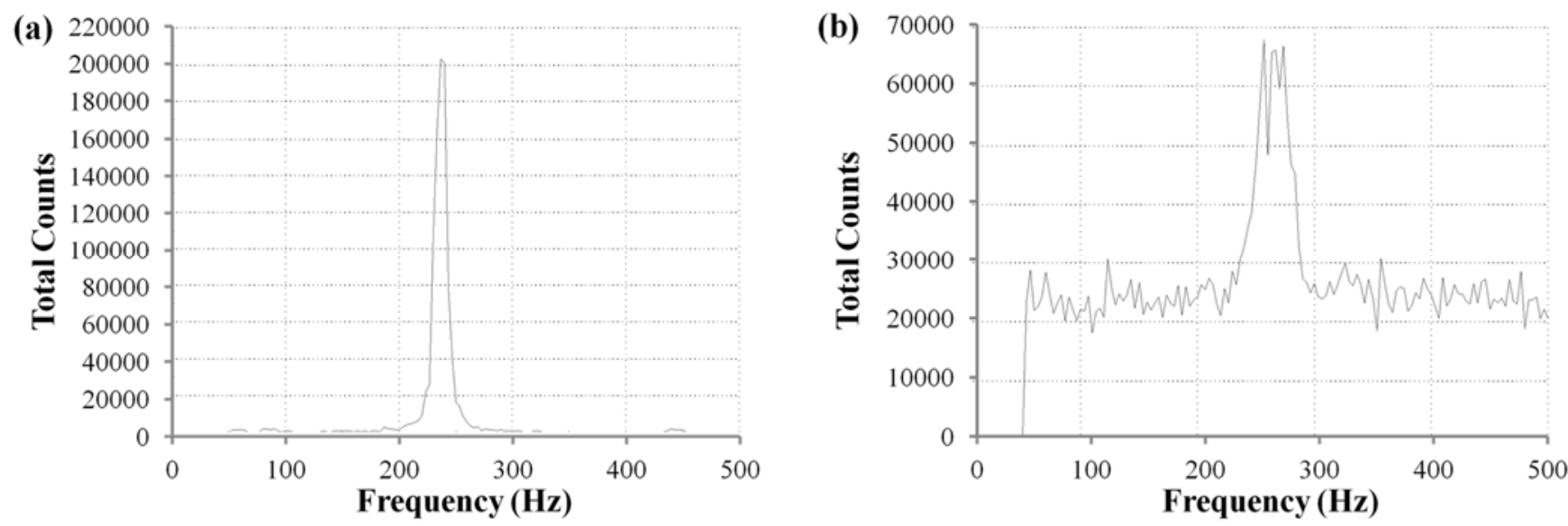

Fig. B.6. (a) Frequency plot obtained for the measurement of negative standard (Malvern, DTS1235, Batch: 091408, - $42 \pm 4.2 \mathrm{mV}$, Expiration date: February 2015, Analysis date: May 2014), measurement value: - $41.1 \pm 0.7 \mathrm{mV}$ using General Purpose analysis model. (b) Frequency plot obtained for the measurement of dispersion $113 \pm 10 \mathrm{~nm}$ (Polysciences Inc, 00876, Batch: 610905) diluted with NaCl 15.4 mM using General Purpose analysis model. Presence of bubbles was observed on the electrodes during examination of the cell recovered right after the measurements were performed.

Factors disturbing the frequency analysis are similar to that causing disturbance on the phase plot as frequency plot corresponds to the Fourier transform analysis of the phase plot.

\section{Mean count rate}

The mean count rate corresponds to the average number of photons detected by the photomultiplier per unit time. It gives the intensity of the signal and is expressed in counts per second (kcps). The mean count rate must be higher than minimum threshold to provide minimal usable signal. However, detectors have maximum count rate value where the response remains linear. The supplier of the instrument recommends to perform measurement within a mean count rate ranging from 20 to $500 \mathrm{kcps}$. It was checked that all measurements were performed within the recommended range of signal.

\section{$\underline{\text { Attenuation }}$}

The attenuation is related to the concentration of the dispersion. The value remained the same considering identical sample measured with the same instrument. 


\section{Conductivity}

The generate electrical field in cell and hence the value of conductivity of the sample must be stable. It was checked that the value of conductivity was the same for identical sample under intermediate precision using the same instrument.

The specification of maximum conductivity of the Zetasizer Nano ZS corresponds to $200 \mathrm{mS} . \mathrm{cm}^{-1}$.

\section{Result Quality Report}

The supplier of the Zetasizer Nano range have developed a quality report to help the interpretation of the data obtained from a zeta potential measurement. The zeta potential quality report includes six tests described in the technical note [3] performed on the raw data for a given sample. A message is displayed in the quality report. If none of the tests fail, the results meets quality criteria. If only one of the tests fail outside specifications, a warning message indicate possible reasons to explain the failure according to the supplier of the instrument. Results from analysis were accepted taking into account results given by quality report. Results were accepted only if all measurements performed on one sample meet quality criteria as reported in the result quality. In case one of the three measurements failed, the analysis was done on a new independent sample.

\section{References}

[1] Malvern, Zetasizer Nanoseries Accessories Guide, Issue 11, April 2013.

[2] Malvern, Technical Note, Concentration Limits for Zeta Potential Measurements in the Zetasizer Nano.

[3] Malvern, Technical Note, Zeta potential quality report for the Zetasizer Nano, 2014 (available on Malvern's site, required registration to access to this note, consulted on May 2015). 


\section{Appendix C: Preparation of measurement cells for surface analysis of the inner part}

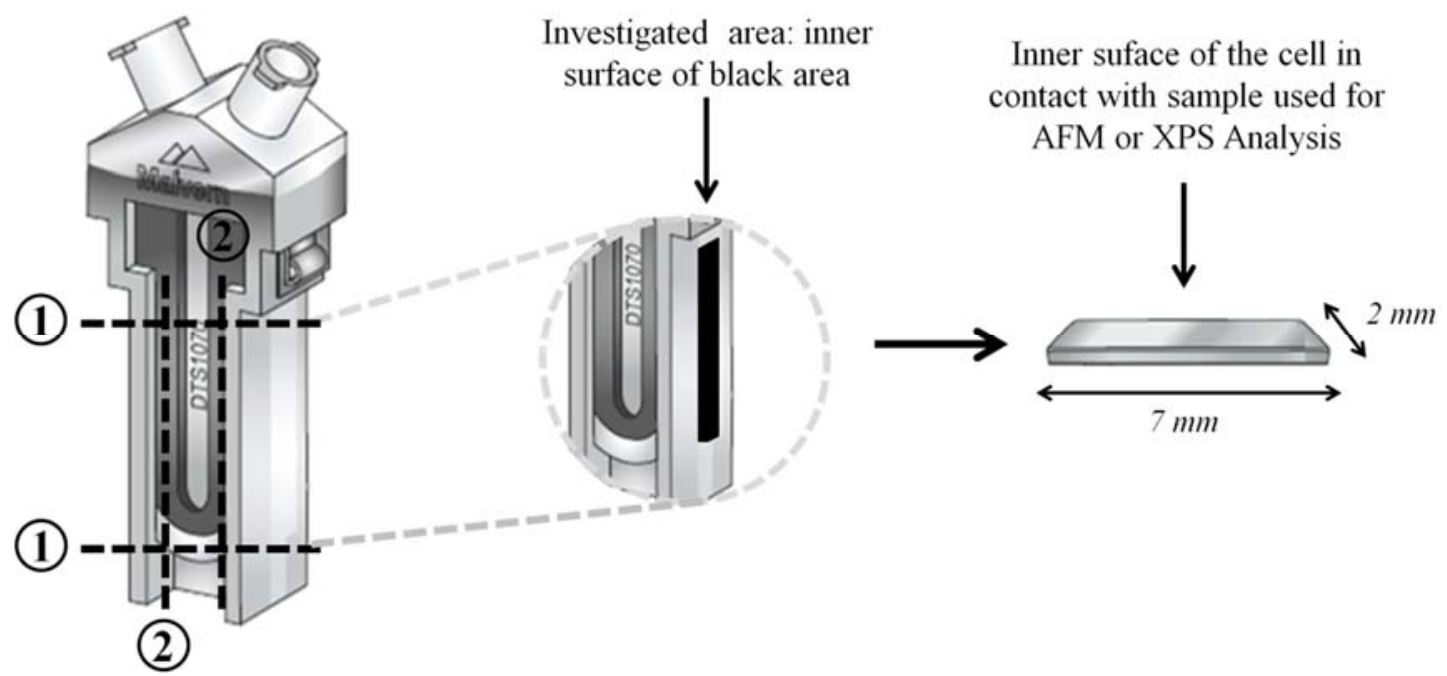

Fig. C.1. Scheme describing the method applied to cut measurement cells to recover a representative face that was in contact with dispersions during measurement of zeta potential or electrophoretic mobility. At first, the lower and upper cell parts were taken off by cutting path 1. Then, the central part was discarded by cutting path 2. The outermost parts of the cell in contact with samples were recovered (blackened area). Parts that were not in contact with samples were discarded. The last piece was sawn into two parts to obtain required size of samples for AFM and XPS analysis. Finally, four parts of dimensions equal to $7 \times 2 \mathrm{~mm}$ were obtained per cell. Cell adapted from [1] with permission.

[1] Malvern, Zetasizer Nanoseries Accessories Guide, Issue 11, April 2013. 


\section{Appendix D. ANOVA table established to interpret designs developed in this study}

Table D.1. ANOVA table for the nested design in which the factors batch of cells (temperature of the sample, type of cells, analyst or day), samples and replicates were studied.

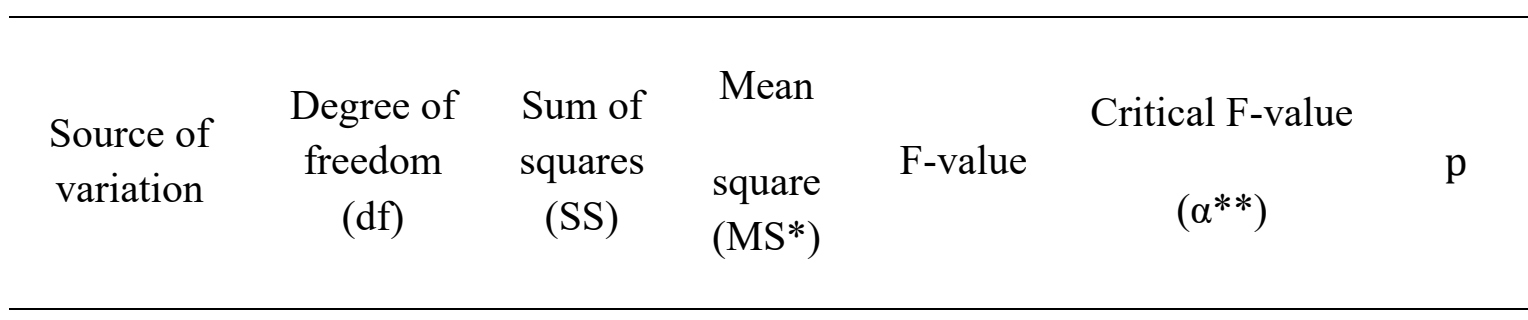

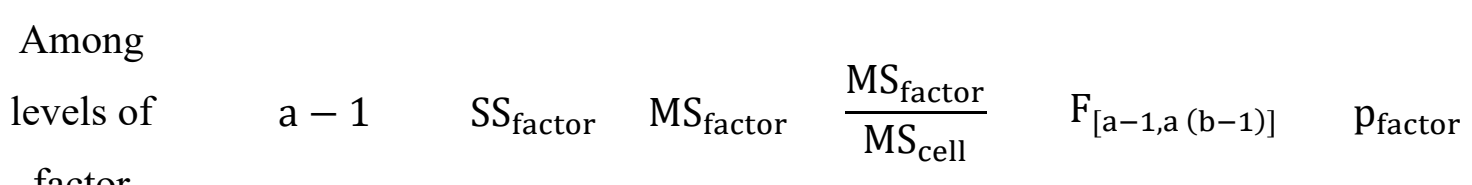

factor

Cells within
factor $\quad \mathrm{a}(\mathrm{b}-1) \quad \mathrm{SS}_{\text {cell }} \quad \mathrm{MS}_{\text {cell }} \quad \frac{\mathrm{MS}_{\text {cell }}}{\mathrm{MS}_{\text {rep }}} \quad \mathrm{F}_{[\mathrm{a}(\mathrm{b}-1), \mathrm{a} \mathrm{b}(\mathrm{n}-1)]} \mathrm{p}_{\text {cell }}$

Replicates

within cells

a b $(n-1) \quad S_{\text {rep }} \quad M_{\text {rep }}$

Total
a b n -1
$\mathrm{SS}_{\text {total }}$
$\mathrm{MS}_{\text {total }}$

$* \mathrm{MS}=\frac{\mathrm{sS}}{\mathrm{df}}$

${ }^{* *} \alpha$ represent the significance level. 


\section{Appendix E. Evaluation of relative standard uncertainty of trueness}

The approach developed by Linsinger in European Reference Materials (ERM) Application Note 1 was used to evaluate the trueness and control whether there was a significant difference between the measurement result and the certified value [1].

The absolute bias, $\Delta_{\mathrm{m}}$, that corresponded to the difference between the mean measured value, $\mathrm{C}_{\mathrm{m}}$, and the certified value, $\mathrm{C}_{\mathrm{CRM}}$, was calculated from Eq. (1).

$\Delta_{\mathrm{m}}=\left|\mathrm{C}_{\mathrm{m}}-\mathrm{C}_{\mathrm{CRM}}\right|$

The uncertainty of the bias, $\mathrm{u}_{\Delta}$, was determined from the uncertainty of the certified value, $\mathrm{u}_{\mathrm{CRM}}$, and the uncertainty of the measurement result, $u_{m}$, according to Eq. (2)

$\mathrm{u}_{\Delta}=\sqrt{\mathrm{u}_{\mathrm{m}}^{2}+\mathrm{u}_{\mathrm{CRM}}^{2}}$

The standard deviation of intermediate precision, $\mathrm{s}_{\text {among days }}$, was divided by the square root of the total number of measurements, $\mathrm{n}^{\prime}$, to obtain $\mathrm{u}_{\mathrm{m}}$ according to Eq. (3).

$\mathrm{u}_{\mathrm{m}}=\frac{\mathrm{s}_{\text {among days }}}{\sqrt{\mathrm{n}^{\prime}}}$

The expanded uncertainty, $\mathrm{U}_{\mathrm{CRM}}$, of the positive standard (certified reference material) was given on the certificate of analysis. The uncertainty of the certified value, $\mathrm{u}_{\mathrm{CRM}}$, was obtained by dividing the expanded uncertainty, $\mathrm{U}_{\mathrm{CRM}}$, by the coverage factor, $\mathrm{k}$, that was provided on the certificate of certified reference material using Eq. (4).

$\mathrm{u}_{\mathrm{CRM}}=\frac{\mathrm{U}_{\mathrm{CRM}}}{\mathrm{k}}$

The expanded uncertainty, $\mathrm{U}_{\mathrm{CRM}}$, of the negative standard (reference material) was given on the certificate, but not, the coverage factor. In some cases, uncertainties without confidence level are merely given as extreme limits between which all values are supposed to be with equally probability (rectangular distribution). If there is a reason to think that values closed to limits are less 
likely than those closed to the center of the range, it is reasonable to assume that zeta potential measurement was triangularly distributed and adopt a coverage factor equal to $\sqrt{6}$ [2].

The expanded uncertainty of the bias, $U_{\Delta}$, was determined according to Eq. (5) with a level of confidence of $95 \%$.

$\mathrm{U}_{\Delta}=2 \cdot \mathrm{u}_{\Delta}$

The bias was compared to its expanded uncertainty: if $\Delta_{\mathrm{m}} \leq \mathrm{U}_{\Delta}$, there was no significant difference between the measurement value and the certified value.

If there was no significant difference between the measurement value and the certified value, the relative standard uncertainty of trueness, $\mathrm{u}_{\mathrm{t}}$, was estimated from the dataset according to Eq. (6).

$\mathrm{u}_{\mathrm{t}}=\frac{\mathrm{u}_{\Delta}}{\mathrm{C}_{\mathrm{m}}}$

The data used for the evaluation of relative standard uncertainty of trueness are given in Table E.1.

Table E.1. Used data for the evaluation of relative standard uncertainty of trueness.

\begin{tabular}{ccc}
\hline Data & Negative standard & Positive standard \\
\hline $\mathrm{C}_{\mathrm{m}}{ }^{*}$ & -42.1 & 2.50 \\
sintermediate precision $^{*}$ & 1.6 & 0.10 \\
$\mathrm{n}^{\prime}$ & 27 & 27 \\
$\mathrm{u}_{\mathrm{m}}{ }^{*}$ & 0.31 & 0.02 \\
$\mathrm{C}_{\mathrm{CRM}}{ }^{*}$ & -42 & 2.53 \\
$\mathrm{U}_{\mathrm{CMR}}{ }^{*}$ & 4.2 & 0.12 \\
$\mathrm{k}$ & $\sqrt{6}$ & 2.5 \\
$\mathrm{u}_{\mathrm{CMR}}{ }^{*}$ & 1.72 & 0.05 \\
$\Delta_{\mathrm{m}}{ }^{*}$ & 0.1 & 0.03 \\
$\mathrm{u}_{\Delta}{ }^{*}$ & 1.8 & 0.06 \\
$\mathrm{U}_{\Delta}{ }^{*}$ & 3.6 & 0.12 \\
$\mathrm{u}_{\mathrm{t}}$ & 4.3 & 2.4 \\
\hline
\end{tabular}

*Units: $\mathrm{mV}$ and $\mu \mathrm{m} . \mathrm{cm} . \mathrm{V}^{-1} \cdot \mathrm{s}^{-1}$ for the negative and positive standards respectively. 


\section{References}

[1] T. Linsinger, ERM Application Note 1: Comparison of a measurement result with the certified value (2005).

[2] Guide to the expression of uncertainty in measurement, JCGM 100:2008 GUM 1995 with minor corrections.

http://www.bipm.org/utils/common/documents/jcgm/JCGM_100_2008_E.pdf (consulted on May 2015). 


\section{Appendix F. Spectral characteristics of dispersions towards the laser wavelength}
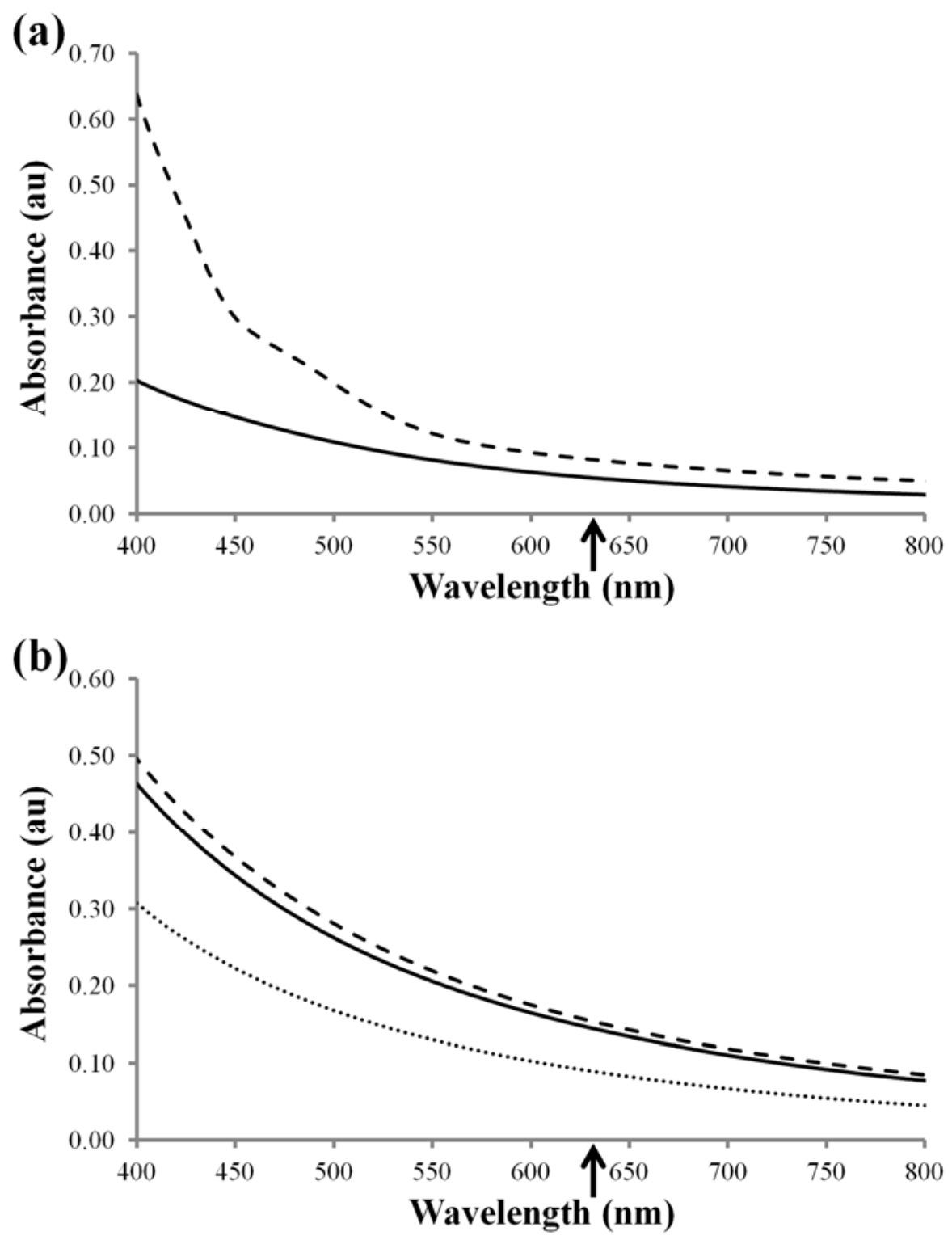

Fig. F.1. (a) Visible spectrum of each standard recorded at $T_{m} 25^{\circ} \mathrm{C}$. Negative standard as provided by the supplier (solid line). Positive standard, $50 \mathrm{mg} \cdot \mathrm{mL}^{-1}$ goethite ( $\left.\alpha-\mathrm{FeOOH}\right)$ (dashed line). (b) Visible spectrum of polymer nanoparticle dispersions recorded at $T_{m} 25^{\circ} \mathrm{C}$. The dispersion of PIBCA nanoparticles decorated with dextran was diluted at a concentration in nanoparticles of $0.16 \mathrm{mg} . \mathrm{mL}^{-1}$ in filtered aqueous solution of sodium chloride $1 \mathrm{mM}$ (solid line). The dispersion of PIBCA nanoparticles decorated with dextran sulfate was diluted at a concentration in nanoparticles of $0.19 \mathrm{mg} . \mathrm{mL}^{-1}$ in filtered aqueous solution of sodium chloride $1 \mathrm{mM}$ (dashed line). The dispersion composed of PIBCA nanoparticles decorated with chitosan was diluted at a concentration in nanoparticles of $0.16 \mathrm{mg} \cdot \mathrm{mL}^{-1}$ in filtered aqueous solution of sodium chloride 1 $m M$ (dotted line). The arrow on the $x$-axis indicated the wavelength of the laser source $(\lambda=633$ nm) mounted in the zeta potential measurement instrument. 


\section{Appendix G. Robustness study - Study of the influence of the batch of cells}

\section{G.1. Results from Ryan-Joiner's and Levene's tests}

(a)

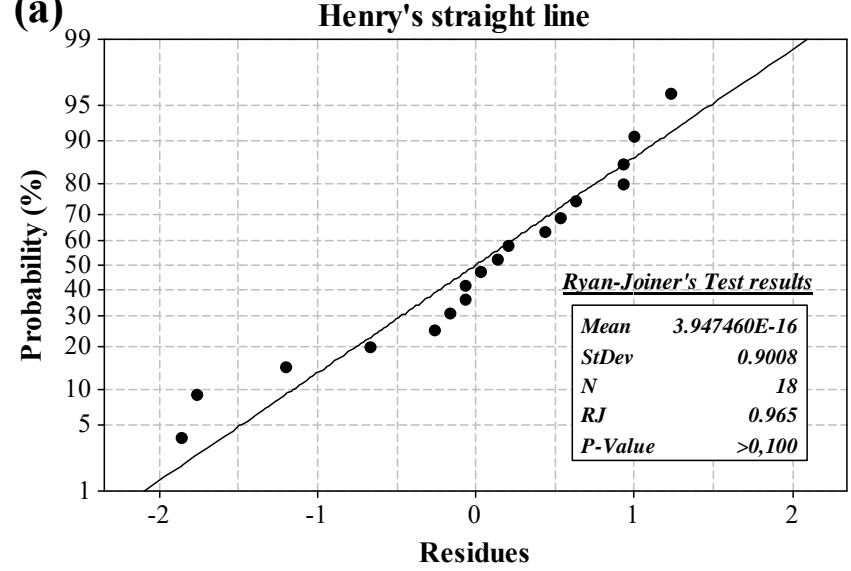

(b)

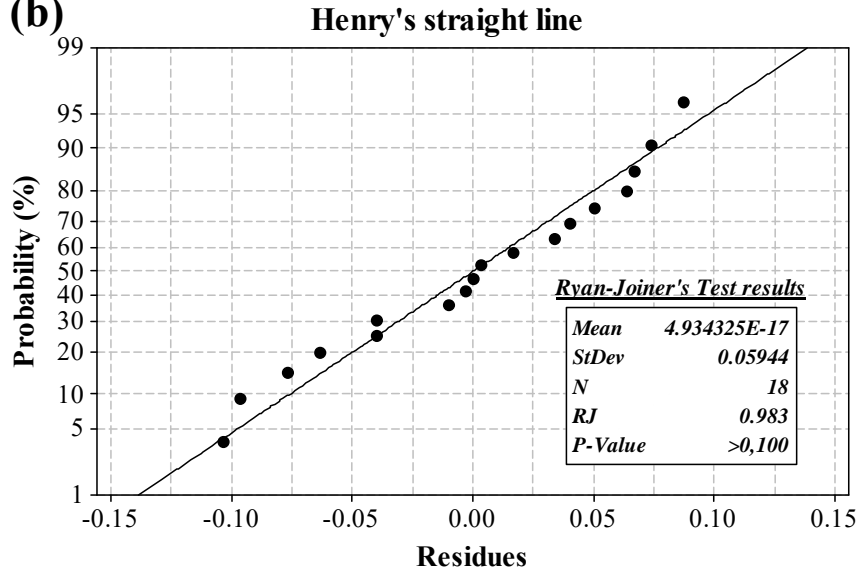

Fig. G.1. Distribution of residues and Ryan-Joiner's Test results for robustness study (influence of the batch of cells). (a) Negative standard. (b) Positive standard.

Table G.1. Levene's test results for robustness study (influence of the batch of cells).

\begin{tabular}{ccc}
\hline Standard & Test statistic & $\mathrm{p}$-value \\
\hline Negative standard & 0.45 & 0.802 \\
Positive standard & 0.27 & 0.919 \\
\hline
\end{tabular}

\section{G.2. ANOVA tables}

Table G.2. ANOVA table for the nested design for the negative standard.

\begin{tabular}{ccccccc}
\hline $\begin{array}{c}\text { Source of } \\
\text { variation }\end{array}$ & $\begin{array}{c}\text { Degree of } \\
\text { freedom } \\
(\mathrm{df})\end{array}$ & $\begin{array}{c}\text { Sum of } \\
\text { squares } \\
(\mathrm{SS})\end{array}$ & $\begin{array}{c}\text { Mean } \\
\text { square } \\
(\mathrm{MS})\end{array}$ & F-value & $\begin{array}{c}\text { Critical F-value } \\
(\alpha=0.05)\end{array}$ & $\mathrm{p}$ \\
\hline $\begin{array}{c}\text { Among } \\
\text { batches }\end{array}$ & 1 & 0.6422 & 0.6422 & 0.252 & 7.71 & 0.642 \\
$\begin{array}{c}\text { Cells within } \\
\text { batches }\end{array}$ & 4 & 10.2089 & 2.5522 & 2.188 & 3.26 & 0.132 \\
$\begin{array}{c}\text { Replicates } \\
\text { within cells }\end{array}$ & 12 & 14.0000 & 1.1667 & & & \\
Total & 17 & 24.8511 & & & & \\
\end{tabular}


Author Manuscript from: Colloids Surf A Physicochem Eng Asp. 2015; 486:218-231.

Table G.3. ANOVA table for the nested design for the positive standard.

\begin{tabular}{ccccccc}
\hline $\begin{array}{c}\text { Source of } \\
\text { variation }\end{array}$ & $\begin{array}{c}\text { Degree of } \\
\text { freedom } \\
(\mathrm{df})\end{array}$ & $\begin{array}{c}\text { Sum of } \\
\text { squares } \\
(\mathrm{SS})\end{array}$ & $\begin{array}{c}\text { Mean } \\
\text { square } \\
(\mathrm{MS})\end{array}$ & F-value & $\begin{array}{c}\text { Critical F-value } \\
(\alpha=0.05)\end{array}$ & $\mathrm{p}$ \\
\hline $\begin{array}{c}\text { Among } \\
\text { batches }\end{array}$ & 1 & 0.027222 & 0.027222 & 4.92 & 7.71 & 0.091 \\
$\begin{array}{c}\text { Cells within } \\
\text { batches }\end{array}$ & 4 & 0.022111 & 0.005528 & 1.10 & 3.26 & 0.399 \\
$\begin{array}{c}\text { Replicates } \\
\text { within cells }\end{array}$ & 12 & 0.060067 & 0.005006 & & & \\
Total & 17 & 0.109400 & & & & \\
\hline
\end{tabular}




\section{Appendix H. Robustness study - Study of the influence of temperature of sample $T_{\text {s }}$}

\section{H.1. Complementary results from the validation of the protocol}

Table H.1. Results obtained for the negative standard for robustness study (influence of $T_{s}$ ).

\begin{tabular}{ccccc}
\multirow{2}{*}{ Sample } & Measurement & \multicolumn{3}{c}{ Zeta Potential (mV)* } \\
& 1 & -45.6 & -42.7 & -45.3 \\
& 2 & -44.6 & -43.1 & -44.5 \\
& 3 & -44.2 & -44.8 & -46.1 \\
\hline & 1 & $-\mathbf{4 7 . 8 * *}$ & -40.7 & -45.9 \\
& 2 & $-\mathbf{4 8 . 8}$ & -43.5 & -44.9 \\
& 3 & $-\mathbf{4 7 . 0}$ & -42.1 & -44.5 \\
\hline \multirow{3}{*}{3} & 1 & -40.7 & -43.9 & -46.0 \\
& 2 & $-38.7^{\circ} * * *$ & -43.3 & -42.5 \\
& 3 & $-38.8^{* * *}$ & -45.9 & -43.1
\end{tabular}

*Reference value: $-42 \pm 4.2 \mathrm{mV}$.

$* *$ Results quality report failed.

*** Low intensity of the signal (23.9 and $29.4 \mathrm{kcps}$ for the second and third measurement of the sample 3 respectively) compared with that obtained in all other measurements ( $>50 \mathrm{kcps})$.

Bold: Out of specification.

Table H.2. Results obtained for the positive standard for robustness study (influence of $T_{s}$ ).

\begin{tabular}{cccc}
\hline \multirow{2}{*}{ Sample } & \multicolumn{3}{c}{ Average electrophoretic mobility $\left(\mu \mathrm{m} . \mathrm{cm} . \mathrm{V}^{-1} \cdot \mathrm{s}^{-1}\right)^{*}$} \\
& $\mathrm{~T}_{\mathrm{s}} 17.5^{\circ} \mathrm{C}$ & $\mathrm{T}_{\mathrm{s}} 20.0^{\circ} \mathrm{C}$ & $\mathrm{T}_{\mathrm{s}} 22.5^{\circ} \mathrm{C}$ \\
\hline 1 & 2.41 & 2.52 & 2.41 \\
2 & $\mathbf{2 . 3 1}$ & 2.54 & 2.54 \\
3 & $\mathbf{2 . 2 7}$ & 2.49 & 2.45 \\
\hline
\end{tabular}

*Reference value: $2.53 \pm 0.12 \mu \mathrm{m} . \mathrm{cm} . \mathrm{V}^{-1} . \mathrm{s}^{-1}$.

Bold: Out of specifications. 


\section{H.2. Results from Ryan-Joiner's and Levene's tests}
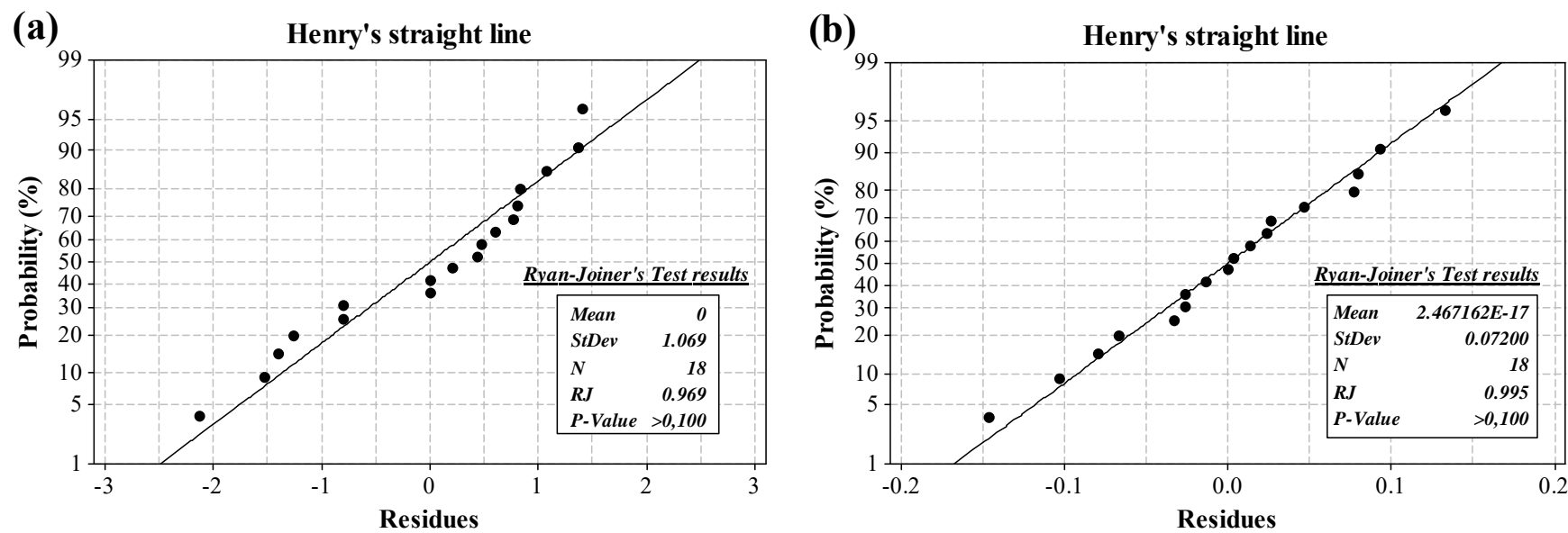

Fig. H.1 Distribution of residues and Ryan-Joiner's Test results for robustness study (influence of $T_{s}$ ). (a) Negative standard. (b) Positive standard.

Table H.3. Levene's test results for robustness study (influence of $T_{s}$ ).

\begin{tabular}{ccc}
\hline Standard & Test statistic & p-value \\
\hline Negative standard & 0.23 & 0.940 \\
Positive standard & 0.72 & 0.621 \\
\hline
\end{tabular}

\section{H.3. ANOVA tables}

Table H.4. ANOVA table for the nested design for the negative standard.

\begin{tabular}{ccccccc}
\hline $\begin{array}{c}\text { Source of } \\
\text { variation }\end{array}$ & $\begin{array}{c}\text { Degree of } \\
\text { freedom } \\
(\mathrm{df})\end{array}$ & $\begin{array}{c}\text { Sum of } \\
\text { squares } \\
(\mathrm{SS})\end{array}$ & $\begin{array}{c}\text { Mean } \\
\text { square } \\
(\mathrm{MS})\end{array}$ & F-value & $\begin{array}{c}\text { Critical F-value } \\
(\alpha=0.05)\end{array}$ & $\mathrm{p}$ \\
\hline Among $\mathrm{T}_{\mathrm{s}}$ & 1 & 9.102 & 9.102 & 3.17 & 7.71 & 0.150 \\
$\begin{array}{c}\text { Cells within } \\
\mathrm{T}_{\mathrm{s}}\end{array}$ & 4 & 11.502 & 2.876 & 1.78 & 3.26 & 0.199 \\
$\begin{array}{c}\text { Replicates } \\
\text { within cells }\end{array}$ & 12 & 19.440 & 1.620 & & & \\
Total & 17 & 40.044 & & & & \\
\hline
\end{tabular}


Table H.5. ANOVA table for the nested design for the positive standard.

\begin{tabular}{ccccccc}
\hline $\begin{array}{c}\text { Source of } \\
\text { variation }\end{array}$ & $\begin{array}{c}\text { Degree of } \\
\text { freedom } \\
(\mathrm{df})\end{array}$ & $\begin{array}{c}\text { Sum of } \\
\text { squares } \\
(\mathrm{SS})\end{array}$ & $\begin{array}{c}\text { Mean } \\
\text { square } \\
(\mathrm{MS})\end{array}$ & F-value & $\begin{array}{c}\text { Critical F-value } \\
(\alpha=0.05)\end{array}$ & $\mathrm{p}$ \\
\hline Among Ts & 1 & 0.009339 & 0.009339 & 1.21 & 7.71 & 0.333 \\
$\begin{array}{c}\text { Cells within } \\
\mathrm{T}_{\mathrm{s}}\end{array}$ & 4 & 0.030822 & 0.007706 & 1.05 & 3.26 & 0.423 \\
$\begin{array}{c}\text { Replicates } \\
\text { within cells }\end{array}$ & 12 & 0.088133 & 0.007344 & & & \\
Total & 17 & 0.128294 & & & & \\
\hline
\end{tabular}




\section{Appendix I. Robustness study - Study of the influence of the type of cells}

\section{I.1. Results from Ryan-Joiner's and Levene's tests}
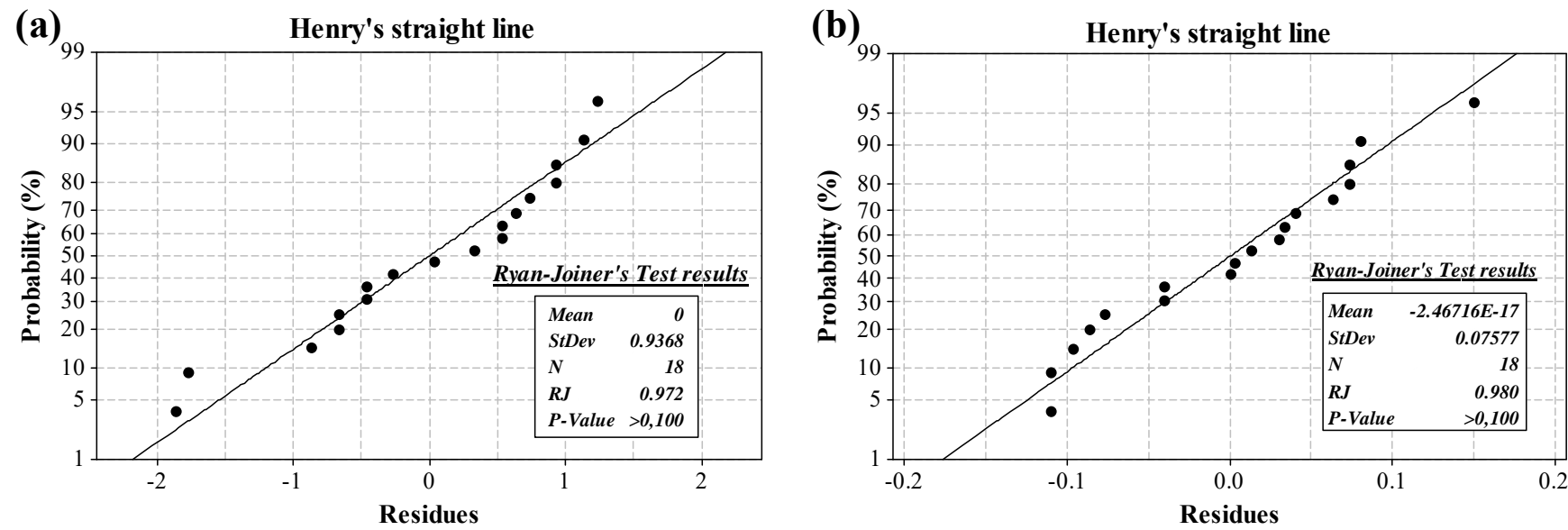

Fig. I.1. Distribution of residues and Ryan-Joiner's Test results for robustness study (influence of the type of cells). (a) Negative standard. (b) Positive standard.

Table I.1. Levene's test results for robustness study (influence of the type of cells).

\begin{tabular}{ccc}
\hline Standard & Test statistic & $\mathrm{p}$-value \\
\hline Negative standard & 0.22 & 0.945 \\
Positive standard & 0.29 & 0.911
\end{tabular}

\section{I.2. ANOVA tables}

Table I.2. ANOVA table for the nested design for the negative standard.

\begin{tabular}{ccccccc}
\hline $\begin{array}{c}\text { Source of } \\
\text { variation }\end{array}$ & $\begin{array}{c}\text { Degree of } \\
\text { freedom } \\
(\mathrm{df})\end{array}$ & $\begin{array}{c}\text { Sum of } \\
\text { squares } \\
(\mathrm{SS})\end{array}$ & $\begin{array}{c}\text { Mean } \\
\text { square } \\
(\mathrm{MS})\end{array}$ & F-value & $\begin{array}{c}\text { Critical F-value } \\
(\alpha=0.05)\end{array}$ & $\mathrm{p}$ \\
\hline $\begin{array}{c}\text { Among } \\
\text { types }\end{array}$ & 1 & 0.720 & 0.720 & 0.70 & 7.71 & 0.450 \\
$\begin{array}{c}\text { Cells within } \\
\text { types }\end{array}$ & 4 & 4.120 & 1.030 & 0.83 & 3.26 & 0.532 \\
$\begin{array}{c}\text { Replicates } \\
\text { within cells }\end{array}$ & 12 & 14.920 & 1.243 & & & \\
Total & 17 & 19.760 & & & & \\
\end{tabular}


Table I.3. ANOVA table for the nested design for the positive standard.

\begin{tabular}{ccccccc}
\hline $\begin{array}{c}\text { Source of } \\
\text { variation }\end{array}$ & $\begin{array}{c}\text { Degree of } \\
\text { freedom } \\
(\mathrm{df})\end{array}$ & $\begin{array}{c}\text { Sum of } \\
\text { squares } \\
(\mathrm{SS})\end{array}$ & $\begin{array}{c}\text { Mean } \\
\text { square } \\
(\mathrm{MS})\end{array}$ & F-value & $\begin{array}{c}\text { Critical F-value } \\
(\alpha=0.05)\end{array}$ & $\mathrm{p}$ \\
\hline $\begin{array}{c}\text { Among } \\
\text { types }\end{array}$ & 1 & 0.001422 & 0.001422 & 0.52 & 7.71 & 0.511 \\
$\begin{array}{c}\text { Cells within } \\
\text { types }\end{array}$ & 4 & 0.010978 & 0.002744 & 0.34 & 3.26 & 0.848 \\
$\begin{array}{c}\text { Replicates } \\
\text { within cells }\end{array}$ & 12 & 0.097600 & 0.008133 & & & \\
Total & 17 & 0.110000 & & & & \\
\hline
\end{tabular}




\section{Appendix J. Robustness study - Study of the influence of the analyst}

\section{J.1. Results from Ryan-Joiner's and Levene's tests}

(a)

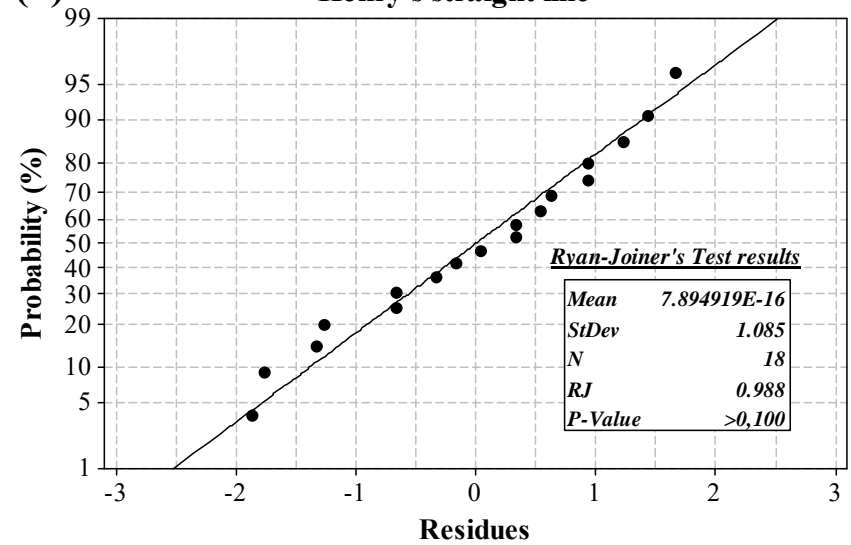

(b)

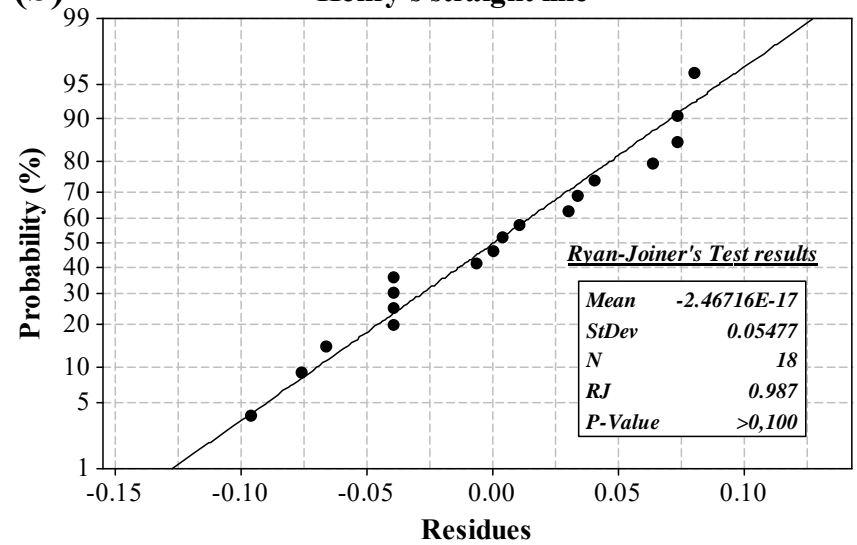

Fig. J.1. Distribution of residues and Ryan-Joiner's Test results for robustness study (influence of the analyst). (a) Negative standard. (b) Positive standard.

Table J.1. Levene's test results for robustness study (influence of the analyst).

\begin{tabular}{ccc}
\hline Standard & Test statistic & $\mathrm{p}$-value \\
\hline Negative standard & 0.27 & 0.923 \\
Positive standard & 0.20 & 0.958
\end{tabular}

\section{J.2. ANOVA tables}

Table J.2. ANOVA table for the nested design for the negative standard.

\begin{tabular}{ccccccc}
\hline $\begin{array}{c}\text { Source of } \\
\text { variation }\end{array}$ & $\begin{array}{c}\text { Degree of } \\
\text { freedom } \\
(\mathrm{df})\end{array}$ & $\begin{array}{c}\text { Sum of } \\
\text { squares } \\
(\mathrm{SS})\end{array}$ & $\begin{array}{c}\text { Mean } \\
\text { square } \\
(\mathrm{MS})\end{array}$ & F-value & $\begin{array}{c}\text { Critical F-value } \\
(\alpha=0.05)\end{array}$ & $\mathrm{p}$ \\
\hline $\begin{array}{c}\text { Among } \\
\text { analysts }\end{array}$ & 1 & 2.1356 & 2.1356 & 4.456 & 7.71 & 0.102 \\
$\begin{array}{c}\text { Cells within } \\
\text { analysts }\end{array}$ & 4 & 1.9156 & 0.4789 & 0.287 & 3.26 & 0.881 \\
$\begin{array}{c}\text { Replicates } \\
\text { within cells }\end{array}$ & 12 & 20.0200 & 1.6683 & & & \\
Total & 17 & 24.0711 & & & & \\
\hline
\end{tabular}


Table J.3. ANOVA table for the nested design for the positive standard.

\begin{tabular}{ccccccc}
\hline $\begin{array}{c}\text { Source of } \\
\text { variation }\end{array}$ & $\begin{array}{c}\text { Degree of } \\
\text { freedom } \\
(\mathrm{df})\end{array}$ & $\begin{array}{c}\text { Sum of } \\
\text { squares } \\
(\mathrm{SS})\end{array}$ & $\begin{array}{c}\text { Mean } \\
\text { square } \\
(\mathrm{MS})\end{array}$ & F-value & $\begin{array}{c}\text { Critical F-value } \\
(\alpha=0.05)\end{array}$ & $\mathrm{p}$ \\
\hline $\begin{array}{c}\text { Among } \\
\text { analysts }\end{array}$ & 1 & 0.000939 & 0.000939 & 0.43 & 7.71 & 0.547 \\
$\begin{array}{c}\text { Cells within } \\
\text { analysts }\end{array}$ & 4 & 0.008711 & 0.002178 & 0.51 & 3.26 & 0.728 \\
$\begin{array}{c}\text { Replicates } \\
\text { within cells }\end{array}$ & 12 & 0.051000 & 0.004250 & & & \\
Total & 17 & 0.060650 & & & & \\
\hline
\end{tabular}




\section{Appendix K. Precision study}

\section{K.1. Results from Ryan-Joiner's and Levene's tests}

(a)

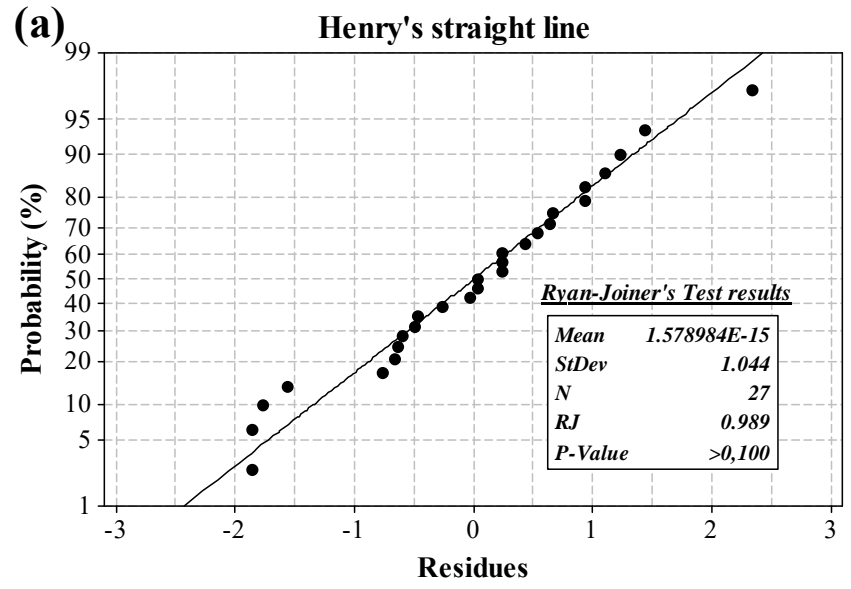

(b) Henry's straight line

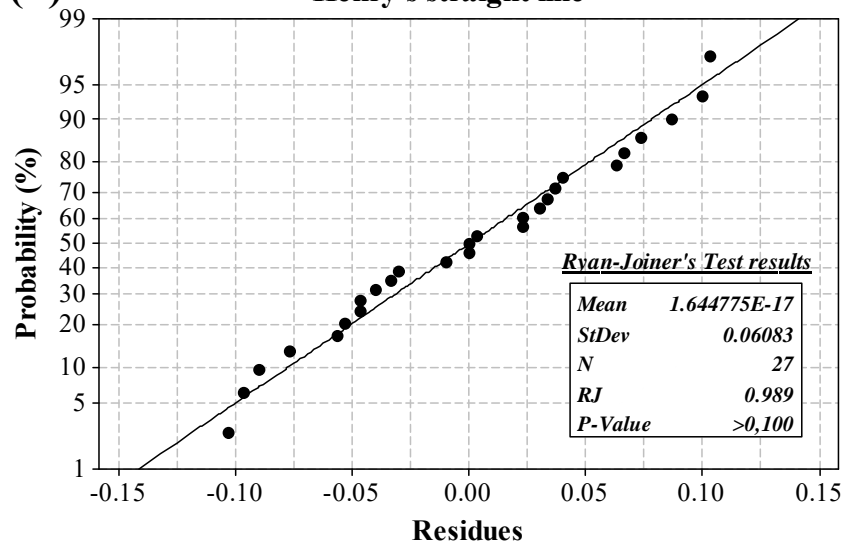

Fig. K.1. Distribution of residues and Ryan-Joiner's Test results for robustness study (precision study). (a) Negative standard. (b) Positive standard.

Table K.1. Levene's test results for robustness study (precision study).

\begin{tabular}{ccc}
\hline Standard & Test statistic & $\mathrm{p}$-value \\
\hline Negative standard & 0.49 & 0.850 \\
Positive standard & 0.27 & 0.977 \\
\hline
\end{tabular}

\section{K.2. ANOVA tables}

Table K.2. ANOVA table for the nested design for the negative standard.

\begin{tabular}{ccccccc}
\hline $\begin{array}{c}\text { Source of } \\
\text { variation }\end{array}$ & $\begin{array}{c}\text { Degree of } \\
\text { freedom } \\
(\mathrm{df})\end{array}$ & $\begin{array}{c}\text { Sum of } \\
\text { squares } \\
(\mathrm{SS})\end{array}$ & $\begin{array}{c}\text { Mean } \\
\text { square } \\
(\mathrm{MS})\end{array}$ & F-value & $\begin{array}{c}\text { Critical F-value } \\
(\alpha=0.05)\end{array}$ & $\mathrm{p}$ \\
\hline $\begin{array}{c}\text { Among } \\
\text { days }\end{array}$ & 2 & 45.2622 & 22.6311 & 22.027 & 5.14 & 0.002 \\
$\begin{array}{c}\text { Cells within } \\
\text { days }\end{array}$ & 6 & 6.1644 & 1.0274 & 0.653 & 2.66 & 0.688 \\
$\begin{array}{c}\text { Replicates } \\
\text { within cells }\end{array}$ & 18 & 28.3333 & 1.5741 & & & \\
Total & 26 & 79.46000 & & & & \\
\hline
\end{tabular}


Table K.3. ANOVA table for the nested design for the positive standard.

\begin{tabular}{ccccccc}
\hline $\begin{array}{c}\text { Source of } \\
\text { variation }\end{array}$ & $\begin{array}{c}\text { Degree of } \\
\text { freedom } \\
(\mathrm{df})\end{array}$ & $\begin{array}{c}\text { Sum of } \\
\text { squares } \\
(\mathrm{SS})\end{array}$ & $\begin{array}{c}\text { Mean } \\
\text { square } \\
(\mathrm{MS})\end{array}$ & F-value & $\begin{array}{c}\text { Critical F-value } \\
(\alpha=0.05)\end{array}$ & $\mathrm{p}$ \\
\hline $\begin{array}{c}\text { Among } \\
\text { days }\end{array}$ & 2 & 0.038230 & 0.019115 & 2.00 & 5.14 & 0.216 \\
$\begin{array}{c}\text { Cells } \\
\text { within days }\end{array}$ & 6 & 0.057333 & 0.009556 & 1.79 & 2.66 & 0.158 \\
$\begin{array}{c}\text { Replicates } \\
\text { within cells }\end{array}$ & 18 & 0.096200 & 0.005344 & & & \\
Total & 26 & 0.191763 & & & & \\
\hline
\end{tabular}




\section{Appendix L. Zeta potential measurements of nanomaterials tested}

The operational qualification was performed with the two standards used for the validation. Zeta potential or electrophoretic mobility must be within range of zeta potential or electrophoretic mobility given on the certificate of analysis of each standard for the negative and positive standards respectively.

Table L.1. Operational qualification of the instrument for nanoparticles bearing negative charges with negative standard.

\begin{tabular}{ccc}
\hline \multirow{2}{*}{ Measurement } & \multicolumn{2}{c}{ Zeta potential $(\mathrm{mV})^{*}$} \\
& Before & After \\
\hline 1 & -44.4 & -44.4 \\
2 & -45.8 & -44.5 \\
3 & -45.3 & -44.4 \\
\hline
\end{tabular}

* Specification: - $42 \pm 4.2 \mathrm{mV}$.

Table L.2. Operational qualification of the instrument for nanoparticles bearing positive charges with positive standard.

Electrophoretic mobility $\left(\mu \mathrm{m} . \mathrm{cm} \cdot \mathrm{V}^{-1} \cdot \mathrm{s}^{-1}\right)^{*}$

\begin{tabular}{cc} 
Before & After \\
\hline 2.59 & 2.59
\end{tabular}

*Specification: $2.53 \pm 0.12 \mu \mathrm{m} . \mathrm{cm} . \mathrm{V}^{-1} \cdot \mathrm{s}^{-1}$. 